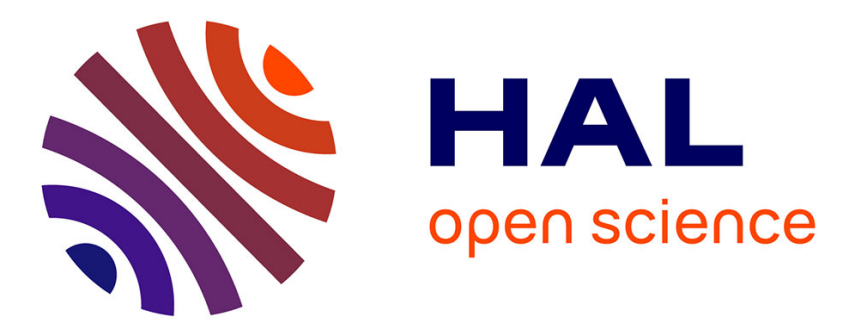

\title{
Geometrical roughness analysis of cement paste surfaces using coherence scanning interferometry and confocal microscopy
}

Komla Lolonyo Apedo, Paul Montgomery, Nicolas Serres, Christophe Fond, Francoise Feugeas

\section{To cite this version:}

Komla Lolonyo Apedo, Paul Montgomery, Nicolas Serres, Christophe Fond, Francoise Feugeas. Geometrical roughness analysis of cement paste surfaces using coherence scanning interferometry and confocal microscopy. Materials Characterization, 2016, 118, pp.212-224. 10.1016/j.matchar.2016.05.023 . hal-02147730

\section{HAL Id: hal-02147730 \\ https://hal.science/hal-02147730}

Submitted on 4 Jun 2019

HAL is a multi-disciplinary open access archive for the deposit and dissemination of scientific research documents, whether they are published or not. The documents may come from teaching and research institutions in France or abroad, or from public or private research centers.
L'archive ouverte pluridisciplinaire HAL, est destinée au dépôt et à la diffusion de documents scientifiques de niveau recherche, publiés ou non, émanant des établissements d'enseignement et de recherche français ou étrangers, des laboratoires publics ou privés. 



\title{
Geometrical roughness analysis of cement paste surfaces using Coherence Scanning Interferometry and Confocal Microscopy
}

\author{
K.L. Apedo ${ }^{a}$, P. Montgomery ${ }^{b}$, N. Serres ${ }^{c}$, C. Fond ${ }^{a}$, F. Feugeas ${ }^{c}$ \\ ${ }^{a}$ ICube, UMR CNRS 7357, Université de Strasbourg, 72 Route du Rhin, F-67400, Illkirch, France; \\ ${ }^{b}$ ICube, UMR CNRS 7357, Université de Strasbourg, 23 rue du Loess, 67037, Strasbourg, France \\ ${ }^{c}$ ICube, UMR CNRS 7357, INSA de Strasbourg, 24 Bld de la Victoire, 67084, Strasbourg, France;
}

Keywords: Cement-based materials; cement paste; geometrical roughness numbers; CSI; SCM; window resizing;

\section{Introduction}

Cement-based materials are heterogeneous, porous and rough composite materials with very complicated microstructures. During their service life, these materials are exposed to environments containing biological agents (microorganisms) and chemical compounds which may or may not be aggressive. The deterioration of cement-based material structures usually starts at the surface and progresses into the material [2]. The main factors that allow the penetration of agressive agents into cement-based materials are their porosity [3-5] and their roughness $[3,4,6,7]$, both of which influence their bioreceptivity which is the ability of the material to be colonized by one or more groups of living organisms [3, 8]. Among the microorganisms able to colonize surfaces, bacteria are known to participate in the first step of biofilm formation.

The size of a bacterium ranges from $0.1 \mu \mathrm{m}$ to $10 \mu \mathrm{m}$ and its shape is variable, ranging from a sphere (for cocci) to rod-shaped (for bacilli) and spiral (for vibrios). Bacterial colonies form clusters which have a size of several tens of micrometers. The multiscale characterization of material surfaces appears to be an important area of the investigation to help provide a better understanding of how these external agents can form biofilms and interact with these surfaces.

The factor that is studied in this paper is the surface roughness. To characterize cementitious material surfaces, standard roughness parameters are often used with topographic reconstruction techniques such as confocal microscopy [1, 9-25] and atomic force microscopy (AFM) [26-41].

Using scanning electron microscopy (SEM) or SEM coupled with energy-dispersive X-ray (EDX), some studies allow the detection of the formation of the microstructures and their chemical composition or provide qualitative analysis of hydration processes and products of cement-based materials [27-32, 41-45].

More recently, [1] have introduced a multiscale analysis of cement paste surface roughness. Two new optical profilometry techniques, coherence scanning interferometry (CSI) and scanning confocal microscopy (SCM) have been used in the surface reconstruction. A new method named "window resizing" has been introduced in the calculation of the standard roughness parameters. The information about the characteristics of the techniques already used in cement-based surface analysis have also been reported in this paper. 
The knowledge of the standard roughness parameters provides the necessary information to understand the process of surfaces colonization by the microorganisms. But this information becomes very limited if it is necessary to go deeper into the knowledge concerning the relation linking the size of the microorganisms and the roughness geometry.

At this point, it then becomes interesting to determine the geometric roughness parameters. This consists of knowing the developed lengths and surfaces.

It should be noted, however that these geometrical parameters may depend on the measurement technique (in terms of its resolution and accuracy). It is also important to consider that the developed surface is a parameter that has no meaning in itself. Only the surface viewed by a probe of a given size has a meaning. Indeed, when the accuracy and the resolution increase (the probe size decreases for example), the surface viewed by the probe increases until it reaches a certain limit. The notion of surface appears subjected to different interpretations with no precise signification and only its projection is quantifiable.

Today, although many studies of cement-based materials have been performed using statistical roughness parameters, to our knowledge, very few investigations have been addressed using geometrical roughness parameters. These parameters, known as roughness $R N$ numbers make it possible to better quantify the developed surface area available for colonization or reaction.

The studies already performed with roughness $R N$ numbers deal with fracture surfaces of hydrated cementbased materials using confocal microscopy $[9-12,16,25,46,47]$. Using a magnification of $\times 90$, (which controls the lateral resolution) and a $z$ slice of $10 \mu m$ (which controls the $z$ resolution), [9] compared the roughness numbers of several specimens of hydrated cement pastes and mortars. A great deal of their study was devoted to the implementation of the confocal technique and software processing of confocal optical sections in digital surface topographic maps. It has also been found that the fracture surface areas of cement paste are 1.8 times greater than the nominal projected surface areas and that of mortars range from 2.4-2.8 times greater than the nominal surface areas.

[10] have extended the analysis of [9] to the study of the correlation between the roughness numbers of fracture surfaces and the mechanical parameters such as critical stress intensity factor $K_{I c}$, critical effective crack length $a_{c}$, compressive strength $\sigma_{c}$, total porosity and effective pore diameter. These analyses pointed to a strong correlation between roughness numbers and stress intensity factor $K_{I c}$ as well as crack length $a_{c}$ whereas only a weak correlation has been observed with the compressive strength $\sigma_{c}$. Almost no correlation has been found for all the other material properties (total porosity and effective pore diameter). The paper also addresses the fractal dimension calculation as a function of the roughness numbers. Testing a notched concrete beam using three-point bending, [11] used confocal microscopy to analyze the region near the interface between the cement paste and the aggregate. The roughness numbers in the proximity of the paste-aggregate interface has been found to be higher than that of the paste outside the interface. A correlation between the critical stress intensity factor $K_{I c}$, the critical crack extension $\delta a_{c}$ and the roughness of the fracture surfaces of cement-based materials has been found. [46] analyzed using confocal microscopy, the relationship between a cement based material's strength and its roughness $R N$ number. Cement based matrices reinforced by randomly 
dispersed microfibers have been tested using both uniaxial tensile and three-point bending. [12] obtained for cement pastes, the relation $\frac{K_{I c}}{K_{I m}}=\sqrt{R N}$ initially established by [47] for $S_{i}$ single fractured crystals. [12] also established the relation between the roughness number and the fracture toughness values for mortars as $\frac{K_{I c}}{K_{I m}}=R N^{0.45}$. [16] demonstrated the potential applications of confocal microscopy through surface roughness measurements using $R N$ numbers. [25] introduced a new roughness parameter known as fractal roughness number $R n_{o}$ which is scale-dependent only within the region of fractality of fractured cement pastes. This new parameter has been shown to be lower than the ordinary roughness number $R N$. The relationship between the water-to-cement ratio $w / c$ and both $R N$ and $R n_{o}$ have been provided. The correlation between fractured cement paste compressive strength and the roughness numbers $R N$ and $R n_{o}$ has also been investigated.

All these studies lead us to conclude that the roughness $R N$ numbers are very useful for the characterization of cementitious materials. Knowing that these roughness parameters depend on the measuring scale, multiscale analysis seems to be required.

Although CSI showed its performance in the characterization of various kinds of materials [48-58] its use remains relatively unexplored in the field of cement-based materials [1, 59, 60].

In view of the these previous studies, therefore, two things become quite clear. Firstly, the quantitative analysis of the surface roughness of cementitious materials using $R N$ numbers is very important. Secondly, CSI has a great potential in this area but requires careful study to explore the performance, limitations and protocols for successful measurement in view of the high roughness and inhomogeneous nature of cementitious materials.

The present paper extends the work presented in [1]. Both polished and unpolished cement paste surfaces already measured with CSI and SCM and presented in [1] are used to quantify multiscale roughness $R N$ numbers introduced by "window resizing". The paper describes the roughness $R N$ numbers calculation method using "window resizing". The identification of fractal region and its fractal dimension of both polished and unpolished cement pastes is also investigated.

\section{Method}

\subsection{CSI and SCM}

The microscopy techniques (CSI and SCM) used in this paper have already been described in [1]. CSI and SCM are two optical profiling techniques for measuring a material surface's topographic map. These two optical techniques are different due to their accuracy in $Z(0.04 \mu \mathrm{m}$ for CSI and $0.1 \mu \mathrm{m}$ for SCM), their lateral resolutions $(0.45 \mu \mathrm{m}$ for CSI and $2 \mu \mathrm{m}$ for SCM), their $Z$-resolutions (1 $\mathrm{nm}$ for CSI and $10 \mathrm{~nm}$ for SCM) and the extent of the surfaces that they allow to explore $(184 \mu \mathrm{m} \times 138 \mu \mathrm{m}$ for CSI and $4.5 \mathrm{~mm} \times 4.5 \mathrm{~mm}$ for SCM). Thus, the two techniques make it possible to measure the topographic map of surfaces at two different scales. Other characteristics of these techniques can be found in [1].

Areas selected in the middle of the samples were scanned by both techniques.

Using CSI with a camera pixel size of $0.13 \mu m \times 0.13 \mu m$, the scanned areas consisted of $183 \mu m \times 138 \mu m$ for the polished samples and $178 \mu m \times 99 \mu m$ and $69 \mu m \times 55 \mu m$ in the case of the unpolished samples. 
In the case of SCM, the scanned areas consisted of $2 \mathrm{~mm} \times 2 \mathrm{~mm}$ squares and the pixels were recorded every $4 \mu m \times 4 \mu m$.

\subsection{Geometrical parameters measurement by window resizing}

Among the methods that allow the quantification of the surface roughness of cement-based materials, one of the most widely used is the statistical analysis based on the determination of standard roughness parameters such as the amplitude parameters, the spacing parameters and the hybrid parameters [1, 1927, 29, 33, 35, 39, 41, 61]. Among these standard roughness parameters may be mentioned: the altitude difference between the highest and lowest measured points $H_{m m}$ [1], the average of the absolute irregularities $R_{a}[1,19-25,29,35,41,61]$, the root mean square (rms) of the irregularities $R_{q}[1,19,23-27,33,35,39,61]$, the skweness $R_{k s}$ and the kurtosis $R_{k u}[23,25]$. Some of these standard roughness parameters have already been used in conjunction with the window resizing method [1].

A parameter that is also commonly used to quantify the roughness of cementitious materials is the roughness number $R N$. This parameter is generally used to quantify the roughness of fractured surfaces $[12,16,25,46]$ and was also used to quantify the roughness of rubber toughened polymethyl-methacrylate fracture surfaces $[62,63]$. It is defined as the sum of the areas of triangulated surfaces $\left(A_{i}\right)$ in relation to the area of the corresponding nominal surface $\left(A_{p i}\right)$ :

$$
R N=\frac{\sum A_{i}}{\sum A_{p i}}
$$

The reference (nominal) surface is not easy to define. In the literature, a vertical projection of the developed surface onto the horizontal $x y$-plane is often considered as the nominal surface $[12,16,25,29,46]$. More recently, [24] have introduced a new reference surface consisting of the Fourier surface.

In this paper, the developed lengths and surfaces are used to quantify the roughness of cement paste surfaces. The window resizing method whose basis has already been presented in [1], is adopted. Roughness numbers using the developed lengths and surfaces are a new aspect of a roughness quantification implemented in window resizing method.

According to this method, for a given integer $\delta$ (see [1]), the developed lengths and surfaces are calculated on each cell and then the sum of these lengths and surfaces over all the cells is obtained; a cell being defined as a set of points forming a square (see Fig. 1).

Concerning the roughness parameters along $x$ and $y$, the principle is to calculate the ratio between the developed length and the reference length along $x$ and $y$. Thus, a line is defined by specifying either $j$ in the $x$ direction or $i$ in the $y$ direction. The reference (nominal) length $\left(l_{0 x}\right.$ or $\left.l_{0 y}\right)$ is calculated from the end points for each line. The lengths of straight segments between these end points are added up and the sum is calculated in relation to the reference length for each line. The average of the length report is then obtained for $x$ and $y$ directions. The geometrical roughness numbers $R N_{x}$ and $R N_{y}$ are thus defined.

The developed surface is calculated in several ways. In the following, for a given $\delta, p_{1}, p_{2}, p_{3}$ and $p_{4}$ denote the vertices of a basic square and $p_{5}$ is the intersection of the two diagonals (Fig. 1).

The surface area $\left(A_{\alpha}\right)$ of each basic cell is calculated using different techniques : 
- Surface from a diagonal, $s_{14}$ and $s_{23}$ : The diagonal $p_{1}-p_{4}$ is considered; then the surface $s_{14}$ is calculated as the sum of the planar surfaces of the triangles $p_{1}-p_{4}-p_{3}$ and $p_{1}-p_{4}-p_{2}$. Considering the diagonal $p_{2}-p_{3}$, the surface $s_{23}$ is calculated as the sum of the planar surfaces of the triangles $p_{2}-p_{3}-p_{1}$ and $p_{2}-p_{3}-p_{4}$.

- Surface from a midpoint, $s_{p_{5}}$ : The intersection of the two diagonals is defined by $p_{5}$ of which altitude is the average of those of $p_{1}, p_{2} p_{3}$ and $p_{4} . s_{p_{5}}$ is then calculated as the sum of the planar surfaces of the four triangles thus defined.

All these surfaces are known as triangulated surfaces. Using "window resizing", a new type of surface is introduced :

- Warped surface, $s_{q 4}$ : The altitude within a basic cell is interpolated using the interpolation functions of four-node quadrilaterals. The altitude is given by

$$
\tilde{z}=\frac{1}{4}\left[z_{p_{1}}(1-\zeta)(1-\eta)+z_{p_{2}}(1-\zeta)(1+\eta)+z_{p_{3}}(1+\zeta)(1-\eta)+z_{p_{4}}(1+\zeta)(1+\eta)\right]
$$

where $z_{p_{1}}, z_{p_{2}}, z_{p_{3}}$ and $z_{p_{4}}$ are the altitudes of the four vertices of the basic cell.

In the parametric space $\zeta$ and $\eta$ range from -1 to +1 . Using an isoparametric system, the coordinates $(\tilde{x}, \tilde{y})$ are interpolated in the same manner as the functions of $\left(x_{p_{1}}, y_{p_{1}}\right),\left(x_{p_{2}}, y_{p_{2}}\right),\left(x_{p_{3}}, y_{p_{3}}\right)$ and $\left(x_{p_{4}}, y_{p_{4}}\right)$. Thus, $s_{q 4}$ is given by

$$
s_{q 4}=\int d s=\int_{-1}^{+1} \int_{-1}^{+1}\left\|\vec{T}_{\zeta} \wedge \vec{T}_{\eta}\right\| \frac{\partial x}{\partial \zeta} d \zeta \frac{\partial y}{\partial \eta} d \eta
$$

where $\vec{T}_{\zeta}$ and $\overrightarrow{T_{\eta}}$ are the tangent vectors to the warped surface. These vectors are given by

$$
\vec{T}_{\zeta}=\left[\begin{array}{c}
\frac{\partial x}{\partial \zeta} \\
\frac{\partial y}{\partial \zeta} \\
\frac{\partial z}{\partial \zeta}
\end{array}\right] \text { and } \quad \overrightarrow{T_{\eta}}=\left[\begin{array}{c}
\frac{\partial x}{\partial \eta} \\
\frac{\partial y}{\partial \eta} \\
\frac{\partial z}{\partial \eta}
\end{array}\right]
$$

The surface $s_{q 4}$ is then calculated using a numerical integration scheme.

We also introduce a new reference (nominal) surface :

- Reference surface : For a given $\delta$ and for each basic cell, the reference surface area (denoted by $A_{0 \alpha}$ ) is the local plane of the least squares of the analyzed unit cell.

The ratio between the sum of the developed surface areas and the sum of the reference surface areas is then calculated as another roughness parameter $\left(R N_{S}\right)$.

$$
R N_{S}=\frac{A}{A_{0}}, \quad \text { with } \quad A=\sum_{\alpha=1}^{N} A_{\alpha} \quad \text { and } \quad A_{0}=\sum_{\alpha=1}^{N} A_{0 \alpha}
$$

where $N$ stands for the number of basic cells for a given $\delta$.

In this paper, these new geometrical roughness parameters $\left(R N_{S}, R N_{x}, R N_{y}\right)$ are used to compare the different surfaces studied by both techniques. 
It is also important to note that the geometrical parameters may be from the sampling or from the convolution.

For the sampling, the altitudes of the vertices are experimental values obtained from the optical techniques. As the surface obtained by sampling is highly dependent on the measurement technique, (notably its accuracy and resolution), in this paper, another kind of surface known as the convolution surface, is introduced. This surface is one that will be viewed by the bacterial colonies of a given size. So, for the convolution, the altitudes of the vertices are those of the center of a sphere; the radius of this sphere being $\delta d x-\epsilon$, with $\epsilon$ being a small quantity compared with $d x$. Whatever the method (sampling or convolution), the points are taken every $\delta$.

\section{Materials}

The materials used in this paper were already described in [1]. The cement pastes were manufactured using the commercial anhydrous CEM I-52,5R cement (see [1] for its chemical composition) provided by HOLCIM France. A water-to-cement ratio of $w / c=0.4$ was used to guarantee optimum mechanical properties and the samples were manufactured using the ASTM C191 and in accordance with the manufacturer's recommendations for the water-to-cement ratio. Polished and unpolished disk-shaped samples with a diameter of $22 \mathrm{~mm}$ and a thickness of $4 \mathrm{~mm}$ were measured using CSI and SCM (see [1] for the conservation of the samples, the curing times and the polishing process). The polished samples were analyzed in order to go deeper in the understanding of relations between cement surfaces parameters and biocolonisation as the factor that is studied in this paper is the surface roughness. In the scale of investigation with CSI and SCM, the roughness numbers depend on the bulk porosity of the samples. But the roughness of concrete is depending on its composition and its interactions with the mould. So the polishing will allow us to erase the preparation effect and to highlight the impact of porosity on roughness parameters. Note that the polishing was been made after 28 days of curing time, so, those samples made of CEM I-52,5R are hard enough to be polished without damage. To polish samples of this thickness, negatives dedicated to polishing were carried out. These are thicker than the negative used for the implementation of the samples allowing them to exceed $1.5 \mathrm{~mm}$ and being polished with a secure and repeatable way (see Fig. 2).

\section{Results and discussion}

The results of 3D topographic measurements of both polished and unpolished cement paste samples can be found in [1].

\subsection{Results on polished samples}

After comparison, the roughness numbers $R N_{S}$ obtained using the different calculation methods $\left(s_{14}, s_{23}\right.$, $s_{p_{5}}$ and $s_{q 4}$ methods) lead to quite similar results. Thus, for the sake of clarity, in the following, only the results provided by the warped surface method is presented.

Fig. 3 shows the evolution of the roughness number $R N_{S}$ (the sampling is represented by the subscript $e$ and the convolution by the subscript $c$ ) as a function of $\delta$ (or the probe radius, $R_{p}$ in the case of the convolution). Fig. 3(a) corresponds to the evolution of the roughness number $R N_{S}$ as a function of $\delta$ in the case of the samples 
measured with the SCM. This roughness number decreases from 1.02 to 1 for the sample 1 and from 1.016 to 1 for the samples 2 and 3 . These results demonstrate the reproducibility of the samples. The value of $R N_{S}=1$ represents an asymptote to the plot in each case since a developed surface is always greater than a reference surface. A negligible discrepancy was obtained between the results of the three samples. Also, no major difference can be noted between sampling and convolution even if the surface viewed by the bacterial colonies (convolution) is always slightly smaller than the surface provided by the measurement technique (sampling).

Fig. 3(b) corresponds to the evolution of the roughness number $R N_{S}$ as a function of $\delta$ in the case of the sample measured with CSI. This roughness number decreases from 1.79 to 1 . Sampling and convolution plots overlap correctly for $\delta d x \leq 1 \mu m$. A bifurcation occurs for $\delta d x>1 \mu m$. This information suggests that the value of $\delta d x=1 \mu \mathrm{m}$ is a critical value from which the developed surface obtained by the sampling is always very much greater than the surface resulting from the convolution which is the surface viewed by the bacterial colonies. For a bacterial size $<1 \mu \mathrm{m}$, the surface viewed by these bacteria is the surface obtained by CSI. Thus, the SCM technique does not make it possible to know the extent of the bacterial colonization. However for a bacterial size $>1 \mu \mathrm{m}$ the surface viewed by the bacteria is that obtained by the convolution with a sphere of the corresponding size.

Indeed, when $\delta>8$, the discrepancy between the sampling and the convolution becomes large enough because many parts of the sampled surface become inaccessible to the convolution sphere. This effect is illustrated in Fig. 4. Thus, the surface viewed by the bacteria (convolution) is substantially smaller than the surface viewed by the measuring tool (sampling).

In addition, this critical value $(\delta d x=1 \mu \mathrm{m})$ approximately delimits the fractal region of the materials since for $\delta d x \leq 1 \mu \mathrm{m}$, it is possible to find a linear region on the plot (from the second point of the plot to the bifurcation point). It is important to remember that, when the $R N_{S}$ number is plotted as a function of $\delta d x$ on a log-log system, the linear part of the plot determines the region of fractality and the slope of this part determines the fractal dimension as [25] : $D_{S}=2-\alpha$. In this case, after calculation, $D_{S}=2.229$. Thus, only CSI allows access to the fractality region of cement pastes used in this study.

Fig. 3(c) is a superposition of the results from both measurement techniques. This figure shows that the roughness numbers obtained by SCM are always lower than those obtained by CSI. The results also show that CSI and SCM are two different techniques that allow the measurement of the roughness number of cement pastes at two different scales (two different resolutions and accuracies), as the SCM plots overlap with the plots of the results from CSI.

Fig. 5, 6, 7 and 8 show the evolution of the roughness numbers $R N_{x}$ and $R N_{y}$ as a function of $\delta$ (or the probe radius, $R_{p}$ ). The roughness numbers were measured along two perpendicular directions named $x$ and $y$.

Figs 5(a) and 6(a) correspond to the evolution of the roughness numbers $R N_{x}$ and $R N_{y}$ as a function of $\delta$ for the case of the samples measured with SCM. For all these samples, the roughness numbers decrease approximately from 1.013 to 1 . No significant discrepancies were obtained between the convolution and the sampling, even if for a given $\delta$, the sampling results are always slightly greater than the convolution results.

Figs $5(\mathrm{~b})$ and $6(\mathrm{~b})$ correspond to the evolution of the roughness numbers $R N_{x}$ and $R N_{y}$ as a function of $\delta$ 
in the case of the sample measured with CSI. These roughness numbers decrease from 1.457 to 1. Sampling and convolution plots overlap correctly for $\delta d x \leq 1 \mu \mathrm{m}$. A bifurcation occurs for $\delta d x>1 \mu m$. This information indicates once again that the value of $\delta d x=1 \mu \mathrm{m}$ is a critical value from which the roughness number obtained by the sampling is always greater than the roughness number resulting from the convolution. The same conclusion about the fractality region can also be drawn. Using the formula that provides the fractal dimension of profiles $\left(D_{p}=1-\alpha\right.$, where $\alpha$ is the slope of the linear part of the plots in Figs $5(\mathrm{~b})$ and $\left.6(\mathrm{~b})\right)$, respectively 1.140 and 1.143 were found as fractal dimensions for $x$ and $y$ directions. It can be noticed that $D_{S} \approx D_{p x}+D_{p y}$, where $D_{p x}$ and $D_{p y}$ are the fractal dimensions for $x$ and $y$ directions, respectively.

Figs 5(c) and 6(c) are the superpositions of the results from both measurement techniques. These figures show that the roughness numbers obtained with SCM are always lower than the sampling results obtained with CSI. The results show again, that CSI and SCM are two different techniques that allow the measurement of the developed length of cement pastes at two different scales, as the SCM plots overlap with the plots of the results from CSI.

It is important to note that whatever the technique used, the roughness numbers measured along the two perpendicular directions ( $x$ and $y$ ), give identical results (see figs 7 and 8). These results might indicate an isotropy of these polished surfaces in terms of their roughness. The values obtained for fractal dimensions for both directions also support this conclusion.

In the literature, while several authors have addressed the problem of the roughness of cementitious polished samples using standard roughness parameters [26, 27, 29-33, 40,41], to our knowledge, no roughness studies have been performed using RN numbers. Also, except [1] who have adopted a comparative study between SCM and CSI, all existing results use the AFM technique which has major drawbacks of a very small size of the area of interest $(150 \times 150 \mu m$ and a maximum height of a few $\mu m)$ and a long scanning time $[1,53]$.

\subsection{Results on unpolished samples}

As in the case of the polished samples, the surfaces obtained using the different calculation methods lead to quite similar results. Only the results provided by the warped surface technique is then presented in the following.

The evolution of the roughness number $R N_{S}$ as a function of $\delta$ (or the probe radius, $R_{p}$ ) is presented in Fig. 9. In the case of the samples analyzed with SCM (Fig. 9(a)), this number decreases from 1.250 to 1.002 for the sample 1, from 1.232 to 1 for the sample 2 and from 1.222 to 1 for the sample 3 . The plots of the convolution and the sampling overlap each other fairly well and the sampling results are slightly greater than the convolution results.

Fig. 9(b) corresponds to the evolution of the roughness number $R N_{S}$ as a function of $\delta$ in the case of the sample tested with CSI. The ratio decreases from 1.988 to 1.041 for sample 1 and from 1.941 to 1.025 for sample 2. The sampling and the convolution plots overlap correctly for $\delta d x \leq 1 \mu \mathrm{m}$. A bifurcation occurs for $\delta d x>1 \mu m$, leading to the same conclusions as in the case of the polished samples.

The fractal region of these unpolished samples is once again accessible only with CSI. This region corresponds to the points on the plot from the third point on the plot to a point near to the bifurcation point. The calculation 
gives $D_{S}=2.175$ and $D_{S}=2.157$ respectively for samples 1 and 2 . These fractal dimensions are comparable with the value reported in [25] ( $D=2.305)$, and in [64] (Fractal dimension ranging from 2.02 to 2.12). The first authors have tested fractured cement pastes with $w / c=0.4$ after 28 days of hydration and the second ones have studied fractured cement pastes with $w / c=0.3$ and 0.5 after 23 days of hydration.

For the profile fractal dimensions, 1.107 was found as a fractal dimension for both the $x$ and $y$ directions in the case of sample 1 and 1.095 and 1.100 for respectively the $x$ and $y$ directions in the case of sample 2 .

Fig. 9(c) is a superposition of the results from both measurement techniques and serves as a tool for comparing the results from each technique.

The evolution of the roughness numbers $R N_{x}$ and $R N_{y}$ as a function of $\delta$ are presented in Figs 10,11, 12 and 13 .

Figs 10(a) and 11(a) correspond to the evolution of the roughness numbers $R N_{x}$ and $R N_{y}$ as a function of $\delta$ for the case of the samples tested with SCM. For all these samples, the ratios decrease approximatively from 1.013 to 1 . No significant discrepancies were obtained between the convolution and the sampling.

Fig. 10(b) and 11(b) correspond to the evolution of the roughness numbers $R N_{x}$ and $R N_{y}$ as a function of $\delta$ in the case of the samples tested with CSI. These numbers decrease from 1.584 to 1.048 for sample 1 and from 1.551 to 1.025 for sample 2. The sampling and the convolution plots overlap correctly for $\delta d x \leq 1 \mu m$ and a bifurcation occurs for the same value of $\delta$ as in the previous cases.

Figs 10(c) and 11(c) are the superpositions of the results from both measurement techniques. These figures show that the roughness numbers obtained with SCM are always lower than the sampling results obtained with CSI.

It is also important to note that as in the case of the polished samples, whatever the technique used, the roughness numbers measured along the two perpendicular directions ( $x$ and $y$ ), give identical results (see figs 12 and 13) indicating an isotropic character of these unpolished cement paste surfaces.

Using the results of this study, CSI appears as a very interesting tool for studying both polished and unpolished cement paste surfaces. It allows the overcoming of the problems of measurement of too smooth cementitious surfaces with a confocal microscope or very rough cementitious surfaces with AFM.

\section{Conclusions}

In this paper, roughness numbers of both polished and unpolished cement paste samples have been analyzed. The surface of these heterogeneous and porous materials have been characterized using CSI and SCM. The data from both techniques have been used by "window resizing" in the calculation of the roughness numbers along profiles $\left(R N_{x}\right.$ and $\left.R N_{y}\right)$ and on an entire surface $\left(R N_{S}\right)$. The roughness numbers of Both polished and unpolished samples have been quantified. These roughness parameters can be used as quantification tools of the bacterial colonization extent at a given scale.

Despite the limitations of these measuring techniques, the study clearly shows the ability of CSI to analyze very porous and rough surfaces such as cement pastes. The results show that CSI and SCM are two tools that allow the measurement of the surface roughness of the cement pastes at two different scales. The "window 
resizing" technique allows the use of two methods of the calculation of the roughness numbers : the sampling and the convolution. The sampling is the parameter related to the measuring tool while the convolution is the parameter related to the roughness viewed by a bacterium of a given size.

The quantification of developed lengths and surfaces will be very useful in the further analysis of the colonization of cement-based material surfaces by microorganisms and also for other subsequent studies. Four calculation methods of developed surfaces have been implemented in "window resizing" and the results from these methods are identical. The results also show that in term of roughness, cement pastes are relatively isotropic, whether polished or not.

CSI makes it possible to quantify more precisely the surface available for the colonization of bacteria than SCM.

In the case of SCM, whether the samples are polished or not, no major difference can be remarked between sampling and convolution even if the surface viewed by the bacterial colonies (convolution) is always slightly smaller than the surface provided by the measurement technique (sampling).

Using CSI, whether the samples are polished or not, sampling and convolution plots overlay correctly for $\delta d x \leq 1 \mu m$. A bifurcation occurs for $\delta d x>1 \mu m$ and the surface viewed by the bacteria (convolution) is substantially smaller than the surface viewed by the measuring tool (sampling).

It has been found that only CSI allows access to the fractality region of cement pastes used in this study. In future work, the CSI and "window resizing" techniques will be used to perform the roughness characterization of fractured cement pastes. It also seems pertinent that extensive studies are required using CSI and "window resizing" to better understand fractal features of fractured cement-based materials such as cement pastes. The relationships between roughness numbers (and/or fractal dimension) and the mechanical properties (compressive strength, Young modulus, toughness and unit failure work) could then be studied. The effect of the curing time on both polished and unpolished cement pastes could also be considered.

\section{References}

[1] K.L. Apedo, C. Munzer, H. He, P. Montgomery, N. Serres, C. Fond and F. Feugeas, Cement paste surface roughness analysis using Coherence Scanning Interferometry and Confocal Microscopy. Materials Characterization, 100 (2015) 108-119. 2, 4, 5, 7, 9

[2] A.I. Abu-Tair, D. Lavery, A. Nadjai, S.R. Rigden and T.M.A. Ahmed, A new method for evaluating the surface roughness of concrete cut for repair or strengthening. Construction and Building Materials, 14 (2000) 171-176. 2

[3] O. Guillitte, Bioreceptivity: A new concept for building ecology studies. Science of the Total Environment, 167 (1995) 215-220 2

[4] S. Manso, W. De Muynck, I. Segura, A. Aguado, K. Steppe, N. Boon and N. De Belie, Bioreceptivity evaluation of cementitious materials designed to stimulate biological growth. Science of the Total Environment, 481 (2014) 232-241. 2 
[5] A. Dubosc, G. Escadeillas, and P.J. Blanc, Characterization of biological stains on external concrete walls and influence of concrete as underlying material. Cement and Concrete Research, 31 (2001) 1613-1617. 2

[6] D. Giannantonio, J.C. Kurth, K.E. Kurtis and P.A. Sobecky, Effects of concrete properties and nutrients on fungal colonization and fouling. International Biodeterioration and Biodegradation, 63 (2009) 252-259. 2

[7] D. Brajkovic, D. Antonijevic, P. Milovanovic, D. Kisic and K. Zelic, Surface characterization of the cement for retention of implant supported dental prostheses : In vitro evaluation of cement roughness and surface free energy. Applied Surface Science, 311 (2014) 131-138. 2

[8] O. Guillitte and R. Dreesen, Laboratory chamber studies and petrographical analysis as bioreceptivity assessment tools of building materials. Science of the Total Environment, 197 (1995) 365-374. 2

[9] D.A. Lange, H.M. Jennings and S.P. Shah, Analysis of surface roughness using confocal microscopy. Journal of Materials Science, 28 (1993) 3879-3884. 2, 3

[10] D.A. Lange, H.M. Jennings and S.P. Shah, Relationship between fracture surface roughness and fracture behavior of cement paste and mortar. Journal of the American Ceramic Society, 76(3) (1993) 589-597. 3

[11] D. Zampini, H.M. Jennings and S.P. Shah, Characterization of the paste-aggregate interfacial zone surface roughness and its relationship to the fracture toughness of concrete. Journal of Materials Science, 30 (1995) 3139-3154. 3

[12] A.B. Abell and D.A. Lange, Fracture mechanics modeling using images of fracture surfaces. International Journal of Solids and Structures, 35 (1998) 4025-4033. 3, 4, 5

[13] J.M. Becker, S. Grousson and M. Jourlin, Surface state analysis by means of confocal microscopy. Cement and Concrete Composites, 23 (2001) 255-259.

[14] R.B. Williamson, Constitutional supersaturation in portland cement solidified by hydration. Journal of Crystal Growth, 34 (1968) 787-794.

[15] A.M. Rashed, The Microstructure of Air-entrained Concrete. UC Berkeley Dissertation, (1989).

[16] K.E. Kurtis, N.H. El-Ashkar, C.L. Collins and N.N. Naik, Examining cement-based materials by laser scanning confocal microscopy. Cement and Concrete Composites, 25 (2003) 695-701. 3, 4, 5

[17] M.K. Head and N.R. Buenfeld, Confocal imaging of porosity in hardened concrete. Cement and Concrete Research, 36 (2006) 896-911.

[18] A.B. Nichols and D.A. Lange, 3D surface image analysis for fracture modeling of cement-based materials. Cement and Concrete Research, 36 (2006) 1098-1107.

[19] Tomás Ficker, Fracture Surfaces of Cement-Based Materials and Porous Rocks Investigated by Confocal Microscopy. International Scientific Conference MSFE, September 2010, Octrava, Czech Republic. 5 
[20] T. Ficker, D. Martisek and H.M. Jennings, Surface roughness and porosity of hydrated cement pastes. Acta Polytechnica, 51 (2011) 7-20.

[21] T. Ficker, Fracture Surfaces of Porous Materials. Acta Polytechnica, 51 (2011) 21-24.

[22] T. Ficker, Surface Morphology of Porous Cementitious Materials Subjected to Fast Dynamic Fractures. Acta Polytechnica, 51 (2011) 118-119.

[23] T. Ficker, Fracture surfaces and compressive strength of hydrated cement pastes. Construction and Building Materials, 27(1) (2012) 197-205. 5

[24] Tomás Ficker and Dalibor Martisek, Digital fracture surfaces and their roughness analysis: Applications to cement-based materials. Cement and Concrete Research, 42 (2012) 827-833. 5

[25] Tomás Ficker, Dalibor Martisek and Hamlin M. Jennings, Roughness of fracture surfaces and compressive strength of hydrated cement pastes. Cement and Concrete Research, 40 (2010) 947-955. 2, 3, 4, 5, 8, 10

[26] Mahalia Miller, Christopher Bobko, Matthieu Vandamme and Franz-Josef Ulm, Surface roughness criteria for cement paste nanoindentation. Cement and Concrete Research, 38 (2008) 467-476. 2, 9

[27] L. Ferrari, J. Kaufmann, F. Winnefeld and J. Plank, Reaction of clinker surfaces investigated with atomic force microscopy. Construction and Building Materials, 35 (2012) 92-96. 2, 5, 9

[28] A. Peled, J. Castro and W.J. Weiss, Hydrated cement paste constituents observed with Atomic Force and Lateral Force Microscopy. Construction and Building Materials, 25 (2011) 4299-4302.

[29] A. Peled, J. Castro and W.J. Weiss, Atomic force and lateral force microscopy (AFM and LFM) examinations of cement and cement hydration products. Cement and Concrete Composites, 36 (2013) 48-55. 5, 9

[30] V.G. Papadakis and E.J. Pedersen, An AFM-SEM investigation of the effect of silica fume and fly ash on cement paste microstructure. Journal of Materials Science, 34 (1999) 683-690.

[31] T. Yang, B. Keller and E. Magyari Direct observation of the carbonation process on the surface of calcium hydroxide crystals in hardened cement paste using an Atomic Force Microscope. Journal of Materials Science, 38 (2003) 1909-1916.

[32] T. Yang, B. Keller and E. Magyari, AFM investigation of cement paste in humid air at different relative humidities. Journal of Physics D: Applied Physics, 35 (2002) 25-28. 2

[33] Tianhe Yang, AFM study of the interactions between moisture and the surface of cementitious materials. Ph.D. Thesis, Institute of Technology, Zurich, 2006. 5, 9

[34] Kathryn A. Ramirez-Aguilar, David W. Lehmpuhl, Amy E. Michel, John W. Birks and Kathy L. Rowlen, Atomic force microscopy for the analysis of environmental particles. Ultramicroscopy, 77 (1999) 187-194. 
[35] S.R. Mishra, S. Kumar, A. Wagh, J.Y. Rho and T. Gheyi, Temperature-dependent surface topography analysis of Illinois class F fly ash using ESEM and AFM. Materials Letters, 57 (2003) 2417-2424. 5

[36] R.K. Vempati, Ajoy Rao, T.R. Hess, D.L. Cocke and H.V. Lauer Jr., Fractionation and characterization of Texas lignite class 'F' fly ash by XRD, TGA, FTIR, and SFM. Cement and Concrete Research, 24 (1994) 1153-1164.

[37] Y.S. Ibarra, J.J. Gaitero, E. Erkizia and I. Campillo, Atomic force microscopy and nanoindentation of cement pastes with nanotubes dispersion. Physics of the Solid State. 203 (2006) 1076-1081.

[38] P. Mondal, S.P. Shah and L.D. Marks, Use of atomic force microscope and nanoindentation for characterisation of cementitious materials at the nanoscale. In: Proceedings on nanotechnology of concrete: recent developments and future perspectives, ACI SP-254 (2008) 41-49.

[39] P. Mondal, Nanomechanical Properties of Cementitious Materials. Ph.D. Thesis, Northwestern University (2008), Evanston, Illinois. 5

[40] P. Mondal, S.P. Shah and L.D. Marks, A reliable technique to determine the local mechanical properties at the nanoscale for cementitious materials. Cement and Concrete Research, 37 (2007) 1440-1444. 9

[41] I. Zyganitidis, M. Stefanidou, N. Kalfagiannis and S. Logothetidis, Nanomechanical characterization of cement-based pastes enriched with $\mathrm{SiO} 2$ nanoparticles. Materials Science and Engineering B, 176 (2011) 1580-1584. 2, 5, 9

[42] C. Magniont, M. Coutand, A. Bertron, X. Cameleyre, C. Lafforgue, S. Beaufort and G. Escadeillas, A new test method to assess the bacterial deterioration of cementitious materials. Cement and Concrete Research, 41 (2011) 429-438.

[43] Karen L. Scrivener and André Nonat, Hydration of cementitious materials, present and future. Cement and Concrete Research, 41 (2011) 651-665.

[44] Q. Zhang, G. Ye and E. Koenders, Investigation of the structure of heated Portland cement paste by using various techniques. Construction and Building Materials, 38 (2013) 1040-1050.

[45] G. Le Saoût, B. Lothenbach, A. Hori, T. Higuchi and F. Winnefeld, Hydration of Portland cement with additions of calcium sulfoaluminates. Cement and Concrete Research, 43 (2013) 81-94. 2

[46] D.A. Lange, C. Ouyang and S.P. Shah Behavior of cement-based matrices reinforced by randomly dispersed microfibers. Advanced Cement Based Materials, 3 (1996) 20-30. 3, 5

[47] Y.B. Xin, K.J. Hsia and D.A. Lange, Quantitative Characterization of the Fracture Surface of Si Single Crystals by Confocal Microscopy. Journal of the American Ceramic Society, 78 (1995) 3201-3208. 3, 4

[48] P. Montgomery and J.P. Fillard, Peak fringe scanning microscopy (PFSM): submicron 3D measurement of semiconductor components. Proc. SPIE, 1755 (1993) 12-23. 4 
[49] P. Caber, Interferometric profiler for rough surfaces. Applied Optics, 32(19) (1993) 3438-3441.

[50] P.C. Montgomery, A. Benatmane, E. Fogarassy and J.P. Ponpon, Large area, high resolution analysis of surface roughness of semiconductors using interference microscopy. Materials Science and Engineering, B91-92 (2002) 79-82.

[51] P.C. Montgomery, D. Montaner, O. Manzardo, M. Flury and H.P. Herzig, The metrology of a miniature FT spectrometer MOEMS device using white light scanning interference microscopy. Thin Solid Films, 450 (2004) 79-83.

[52] E. Neiss, M. Flury, L. Mager, J.-L. Rehspringer, A. Fort, P. Montgomery, P. Gérard, J. Fontaine and S. Robert, Multi-level Diffractive Optical Elements produced by excimer laser ablation of sol-gel. Optics Express, 16(18) (2008) 14044-14056.

[53] Eric Halter, Paul Montgomery, Denis Montaner, Remi barillon, Mireille Del Nero, Catherine Galindo and Sylvia Georg, Characterization of inhomogeneous colloidal layers using adapted coherence probe microscopy. Applied Surface Science, 256 (2010) 6144-6152. 9

[54] E. Pecheva, P. Montgomery, D. Montaner and L. Pramatarova, White Light Scanning Interferometry Adapted for Large Area Optical Analysis of Thick and Rough Hydroyapatite Layers. Langmuir, 23 (2007) 3912-3918.

[55] P. Montgomery, F. Anstotz, G. Johnson and R. Kiefer, Real time surface morphology analysis of semiconductor materials and devices using 4D interference microscopy. Journal of Materials Science: Materials in Electronics, 19 (2008) 194-198.

[56] P.C. Montgomery, D. Montaner, F. Salzenstein, B. Serio and P. Pfeiffer, Implementation of a fringe visibility based algorithm in coherence scanning interferometry for surface roughness measurement. Proc. SPIE Optical Metrology Munich, Optical Measurement Systems for Industrial Inspection VIII, Eds. P.H. Lehmann, W. Osten \& A. Albertazzi, 13-16 May 2013, Munich, Germany, 8788, DOI: 10.1117/12.927813, ISBN: 9780819491220, 2012.

[57] P. Montgomery, D. Montaner and F. Salzenstein, Tomographic analysis of medium thickness transparent layers using white light scanning interferometry and XZ fringe image processing. Proc. SPIE, Photonics Europe, Optical Micro- and Nanometrology, Eds. C. Gorecki, A.K. Asundi and W. Osten, 16-18 April 2012, Brussels, Belgium, 8430 (2012), DOI: 10.1117/12.927813, ISBN: 9780819491220, 8430.

[58] J. Schmit, J. Reed, E. Novak and J.K. Gimzewski, Performance advances in interferometric optical profilers for imaging and testing. Journal of Optics A: Pure and Applied Optics, 10 (2008) 1-7. 4

[59] Savaş Erdem, Andrew Robert Dawson and Nicholas Howard Thom, Influence of the micro- and nanoscale local mechanical properties of the interfacial transition zone on impact behavior of concrete made with different aggregates. Cement and Concrete Research, 42 (2012) 447-458. 4 
[60] T.C. Chen, C.C. Ferraro, W.Q. Yin, C.A. Ishee and P.G. Ifju, A novel two-dimensional method to measure surface shrinkage in cementitious materials. Cement and Concrete Research, 40 (2010) 687-698. 4

[61] Annika Kauppi, Karin M. Andersson and Lennart Bergström, Probing the effect of superplasticizer adsorption on the surface forces using the colloidal probe AFM technique. Cement and Concrete Research, 35 (2005) 133-140. 5

[62] J.-B. Kopp, J. Schmittbuhl, O. Noel, J. Lin and C. Fond Fluctuations of the dynamic fracture energy values related to the amount of created fracture surface. Engineering Fracture Mechanics, 126 (2014) $178-1895$

63] J.-B. Kopp, J. Schmittbuhl, O. Noel, J. Lin and C. Fond A self-affine geometrical model of dynamic RT-PMMA fractures: implications for fracture energy measurements. International Journal of Fracture, $193(2015)$ 141-152 5

[64] Yuting Wang and Sidney Diamond, A fractal study of the fracture surfaces of cement pastes and mortars using a stereoscopic SEM. Cement and Concrete Research, 31 (2001) 1385-1392. 10 


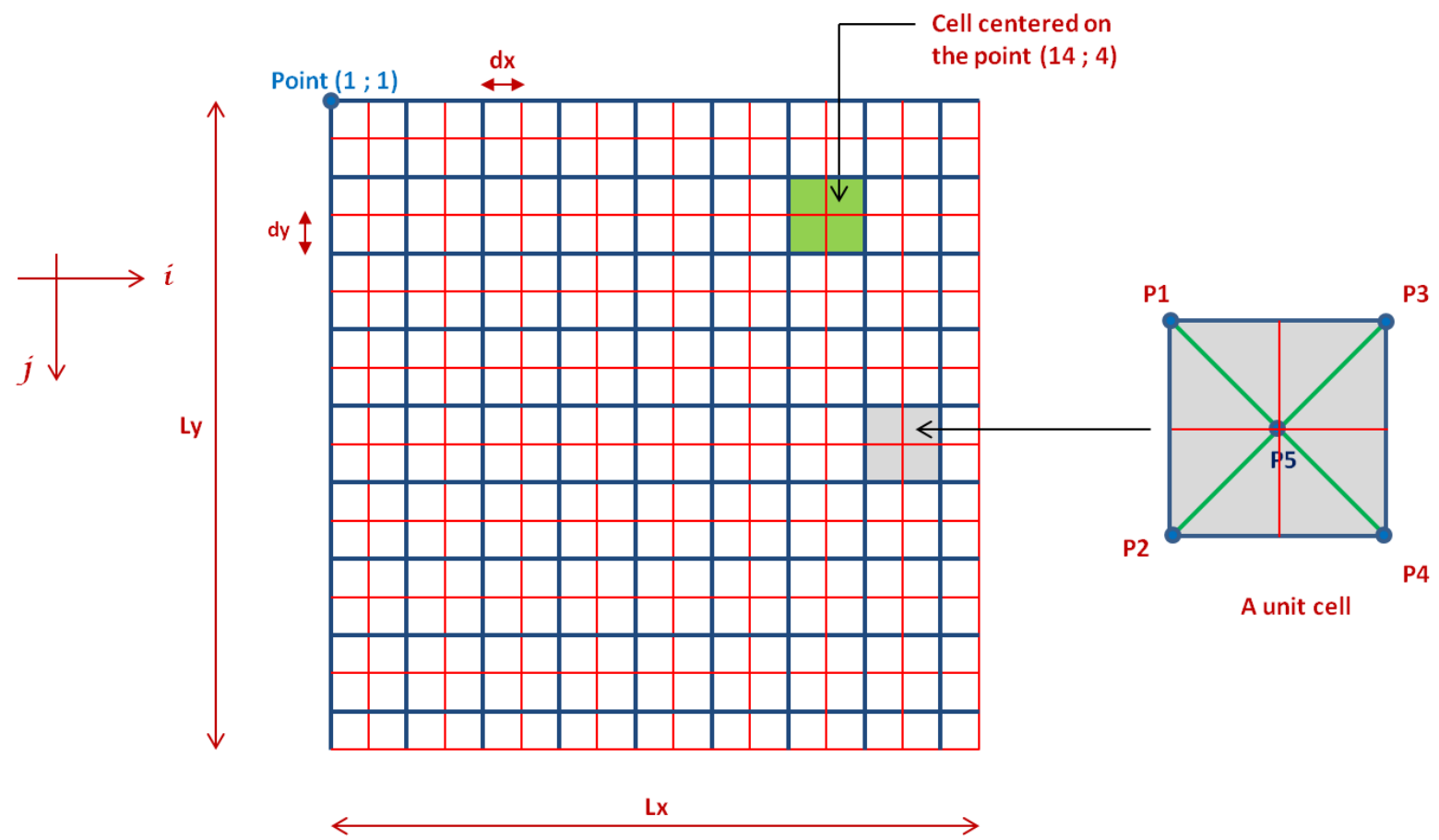

(a)

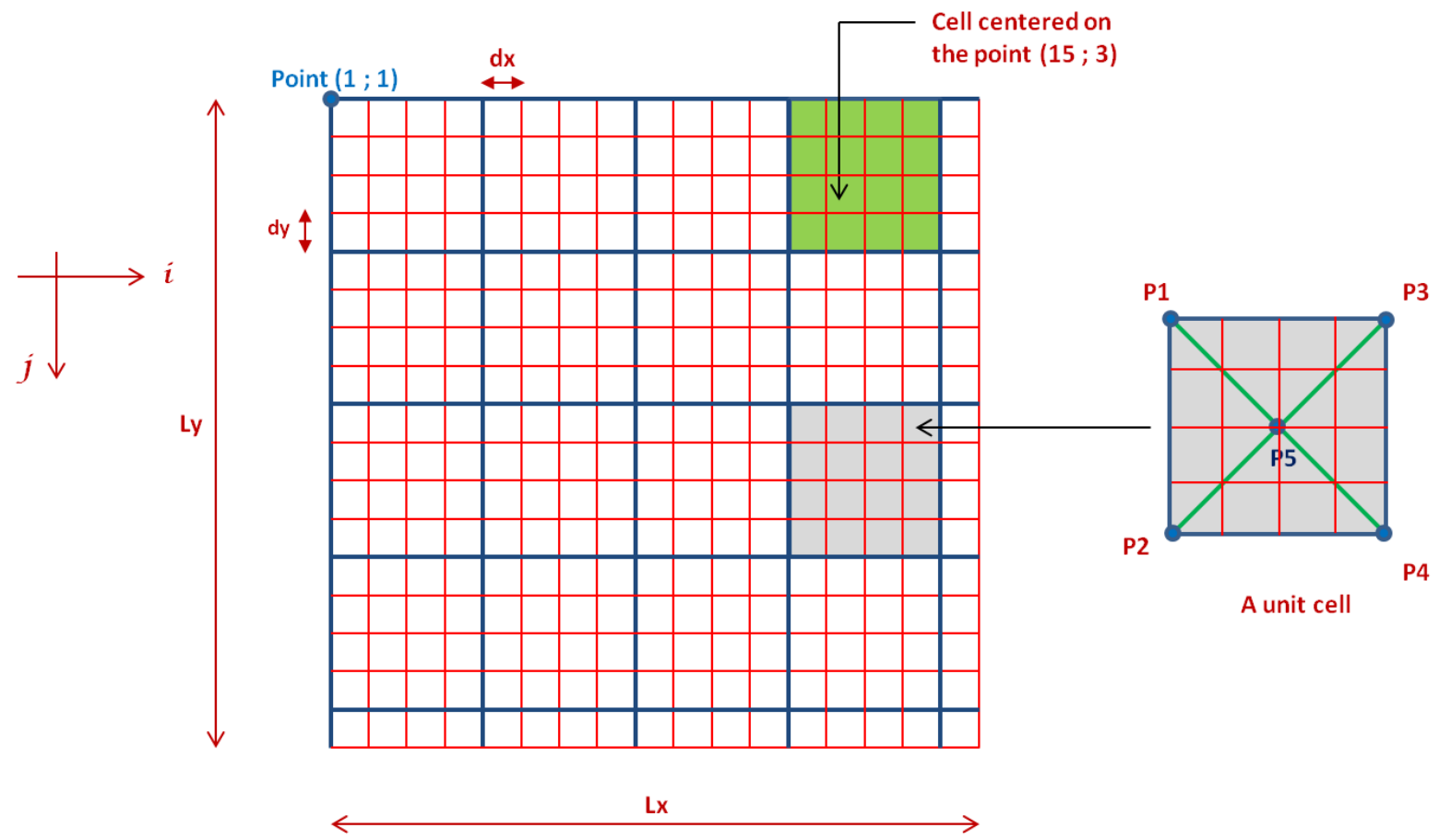

(b)

Figure 1: Decomposition into cells (a) : for $\delta=1$; (b) : for $\delta=2$. 


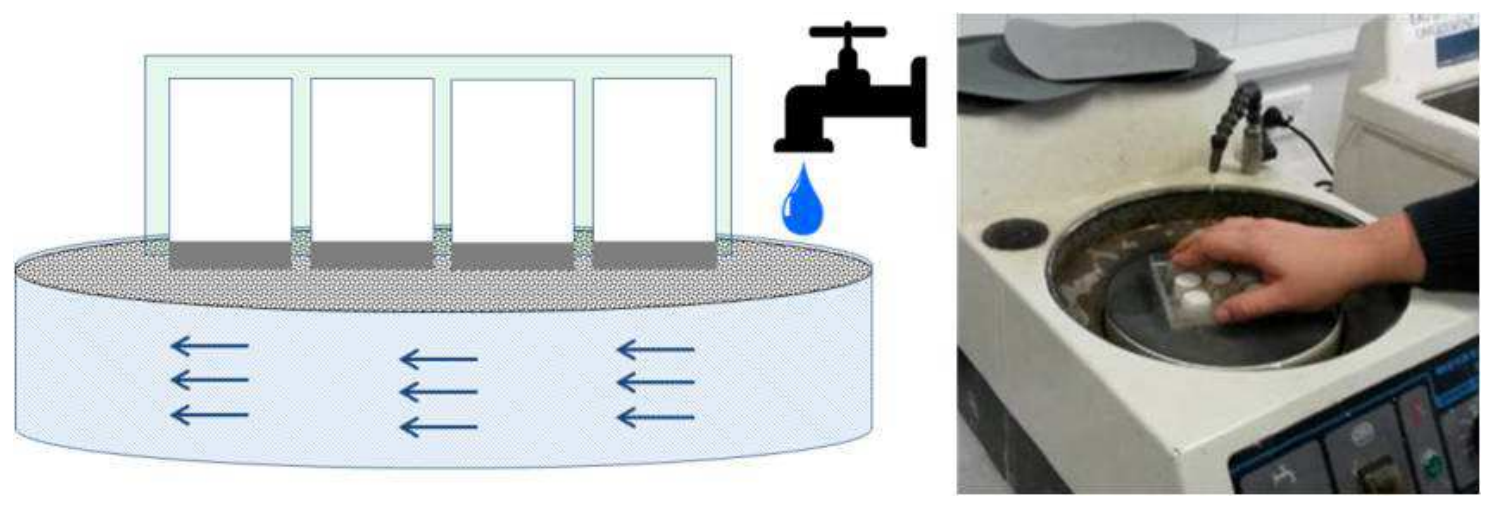

Figure 2: The polishing process. 


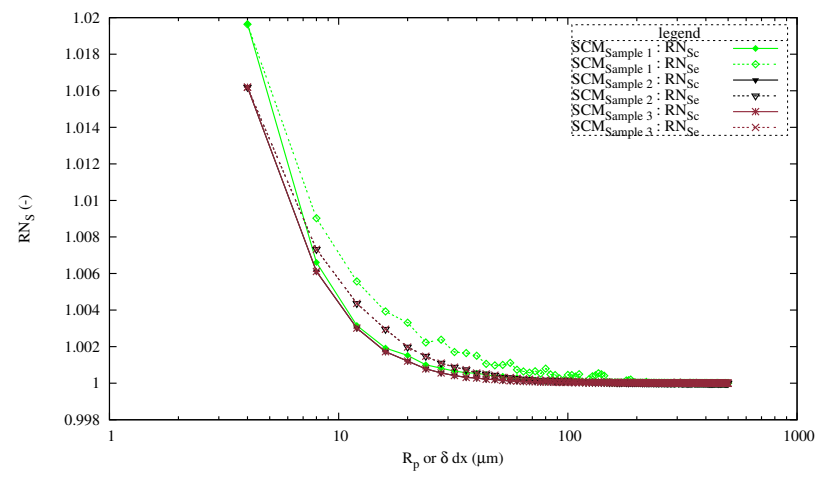

(a)

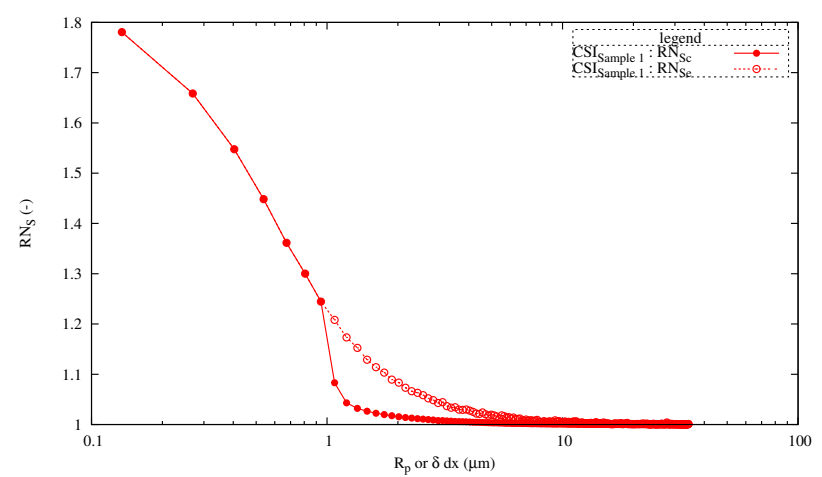

(b)

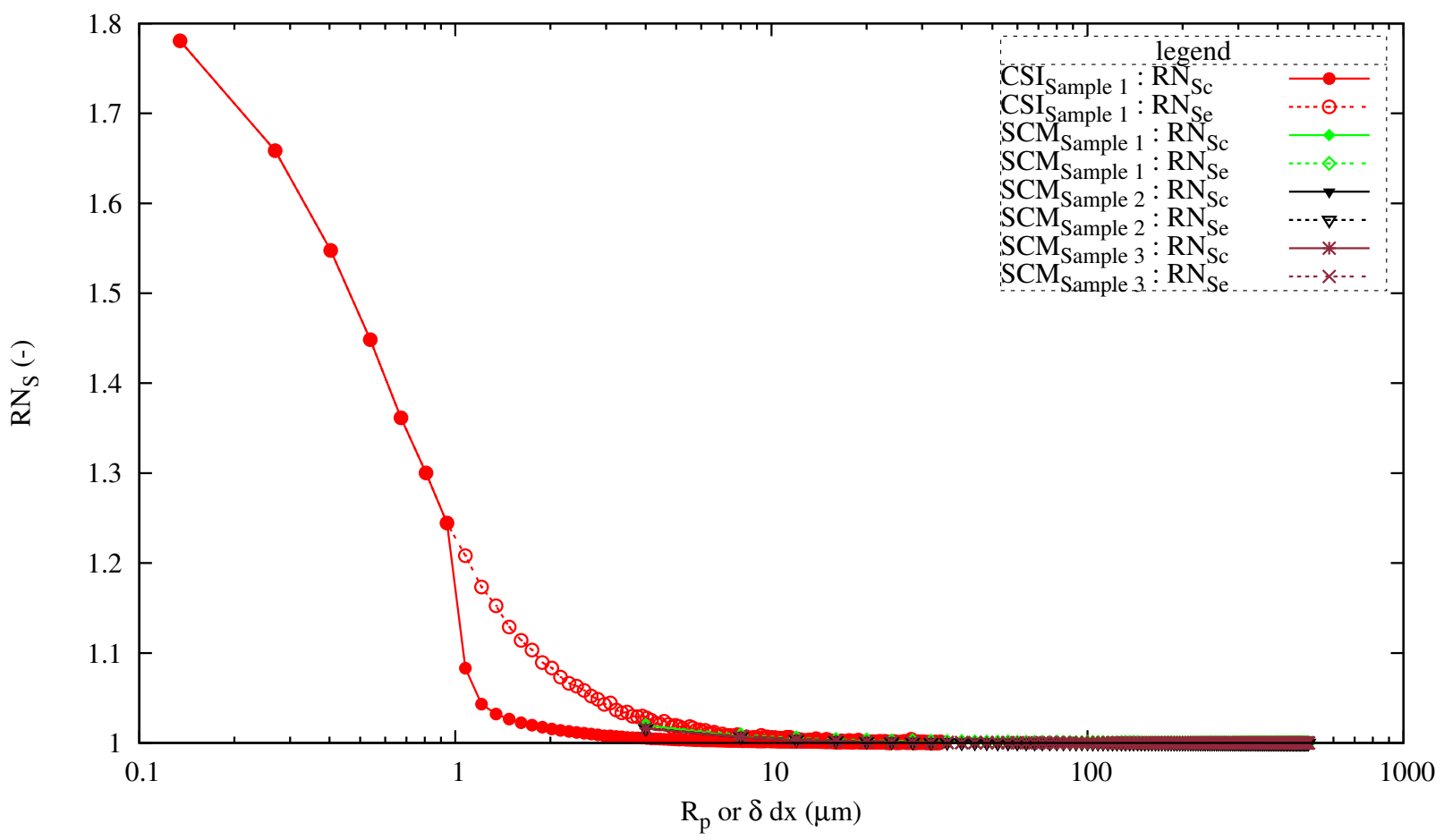

(c)

Figure 3: Roughness number $R N_{S}$ : (a) results from SCM, (b) results from CSI, (c) results SCM vs CSI 


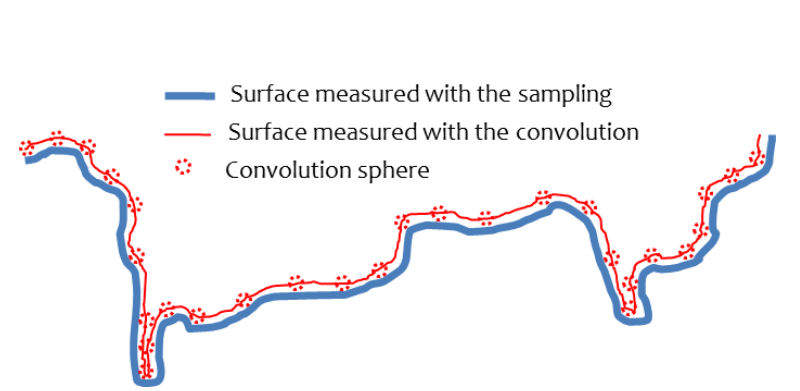

(a)

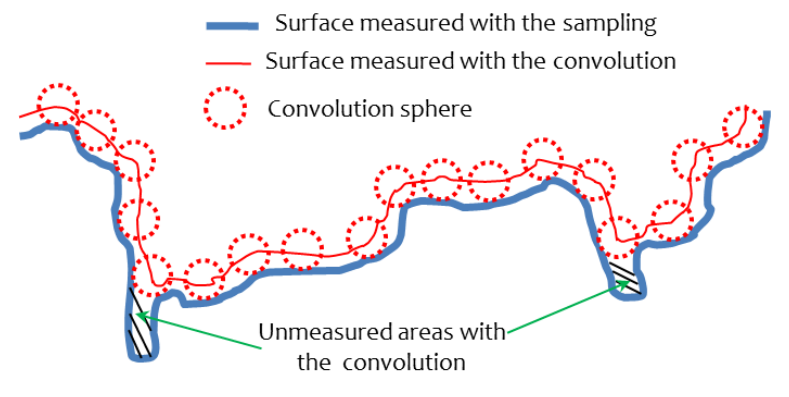

(b)

Figure 4: Measured surfaces using CSI (sampling and convolution) : (a) $\delta \leq 8$, (b) $\delta>8$ 


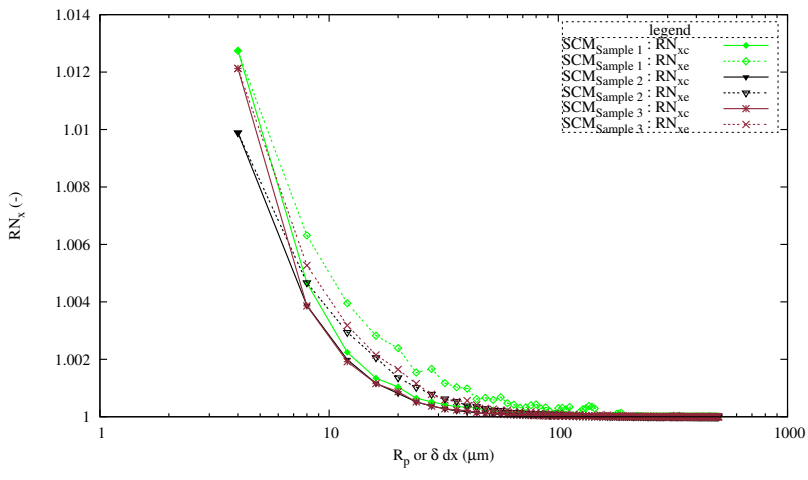

(a)

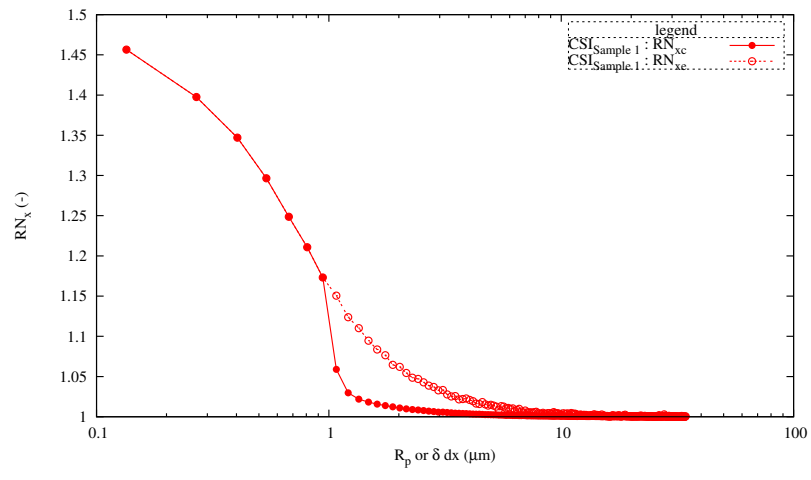

(b)

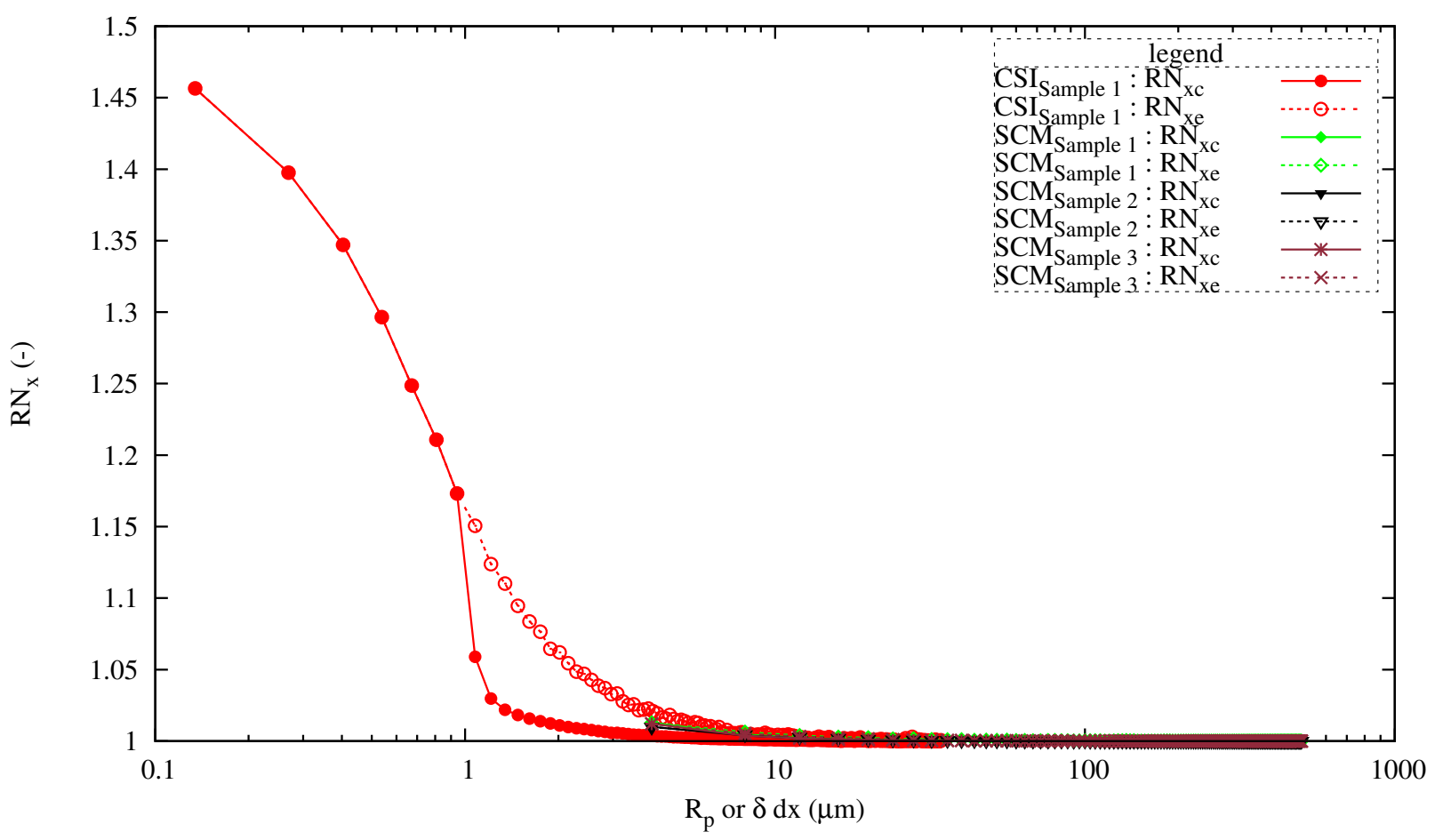

(c)

Figure 5: Roughness numbers along $x$ axis : (a) results from SCM, (b) results from CSI, (c) results SCM vs CSI 


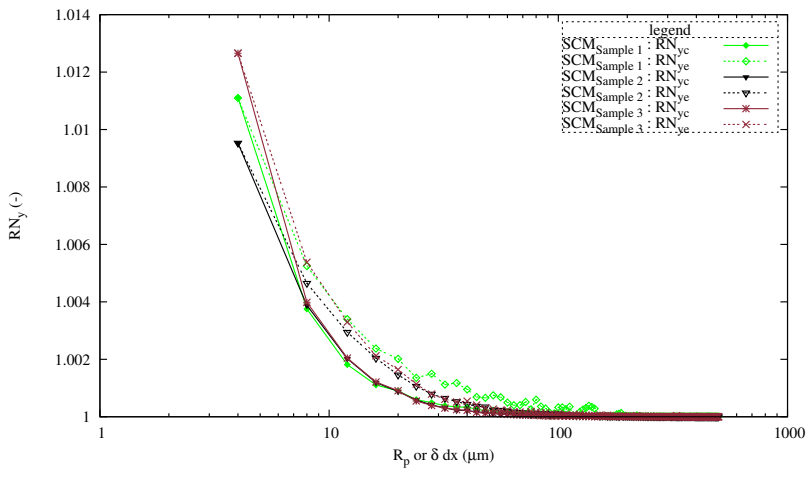

(a)

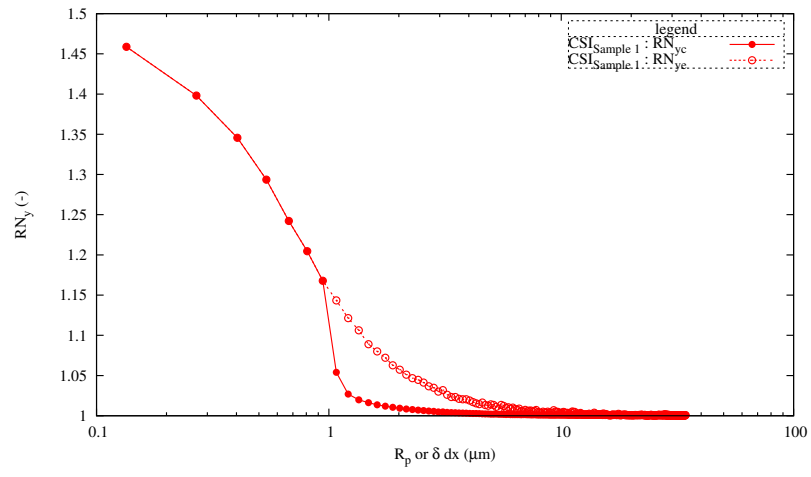

(b)

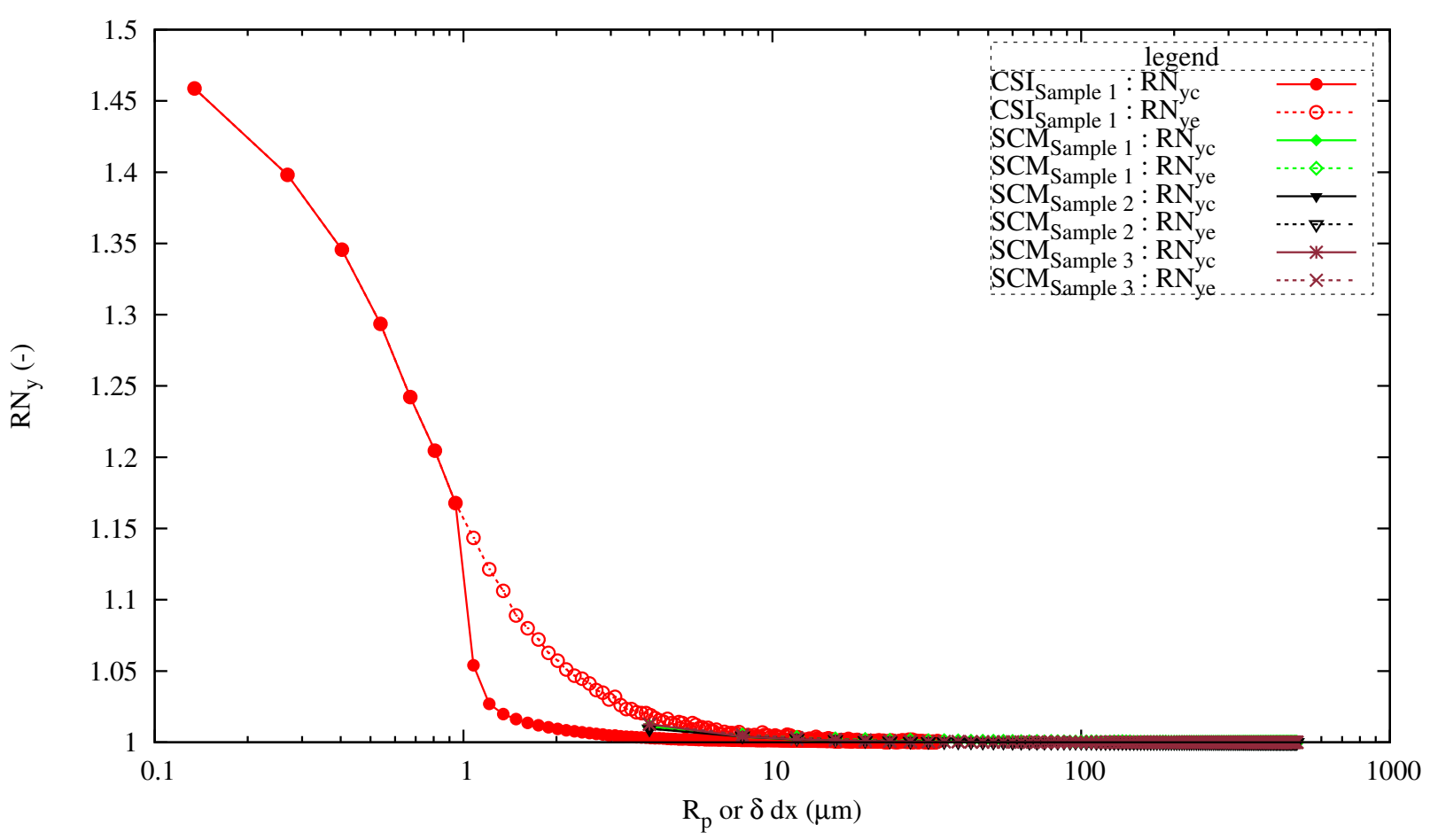

(c)

Figure 6: Roughness numbers along $y$ axis : (a) results from SCM, (b) results from CSI, (c) results SCM vs CSI 


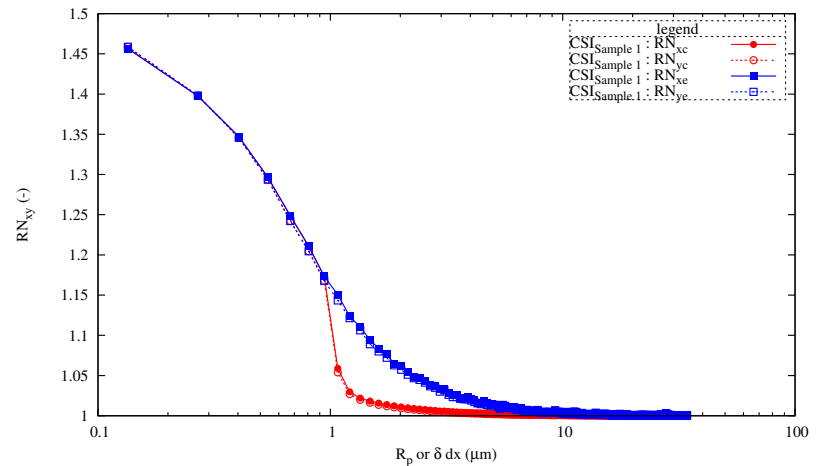

Figure 7: Roughness numbers along both axes in the case of CSI measurements. 


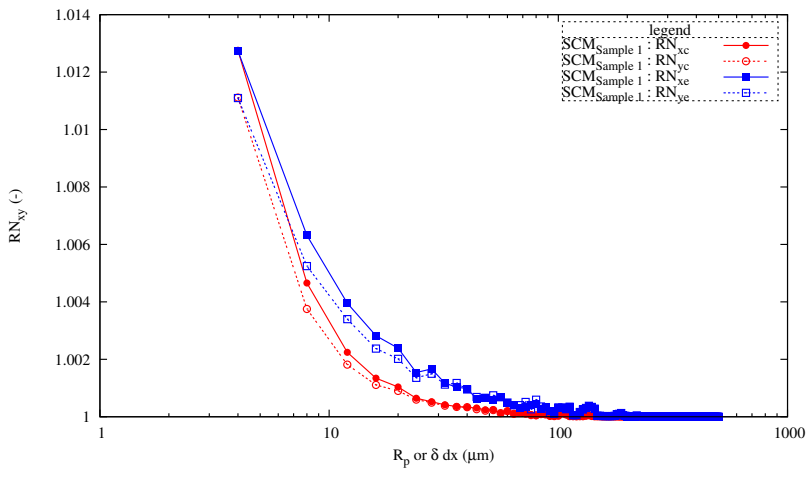

(a)

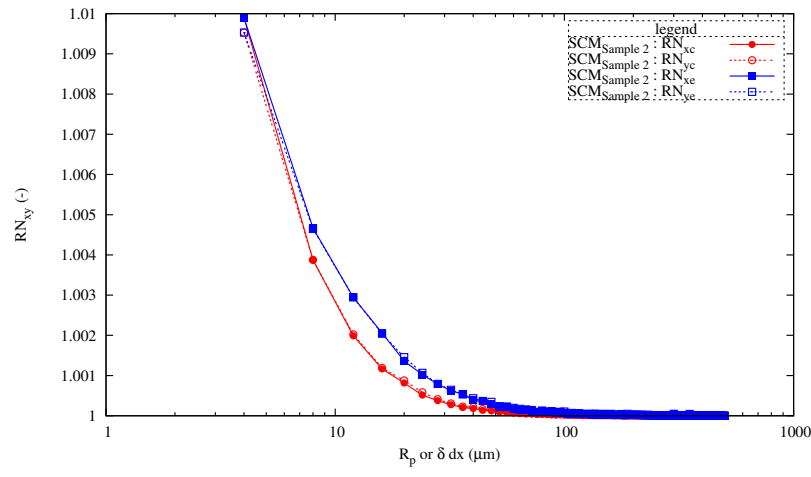

(b)

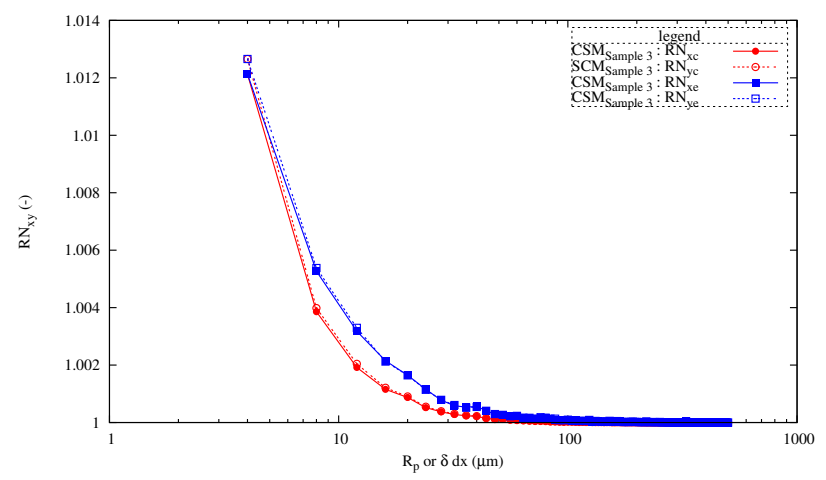

(c)

Figure 8: Roughness numbers along both axes in the case of SCM measurements : (a) results from Sample 1, (b) results from Sample 2, (c) results from Sample 3 


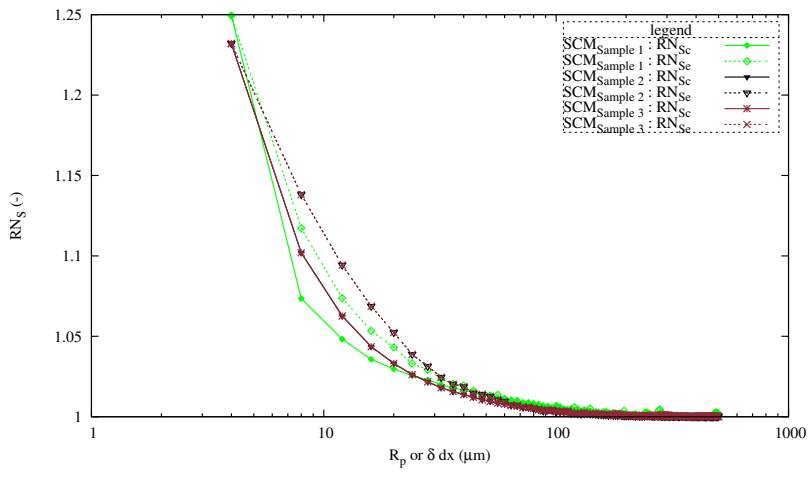

(a)

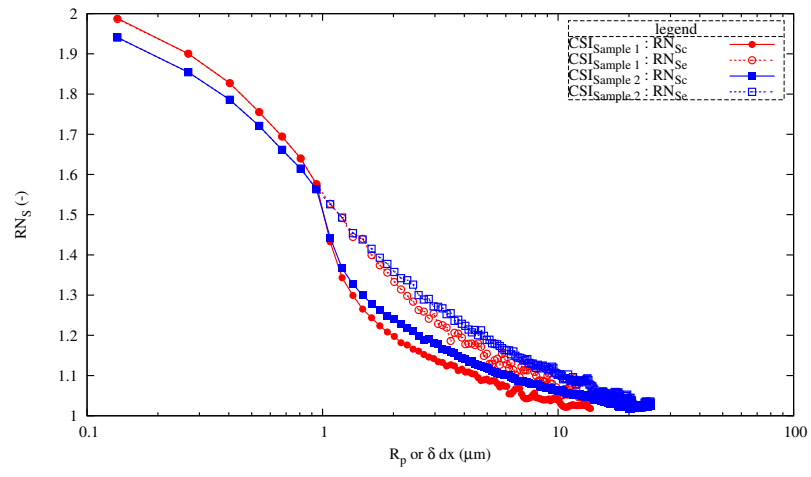

(b)

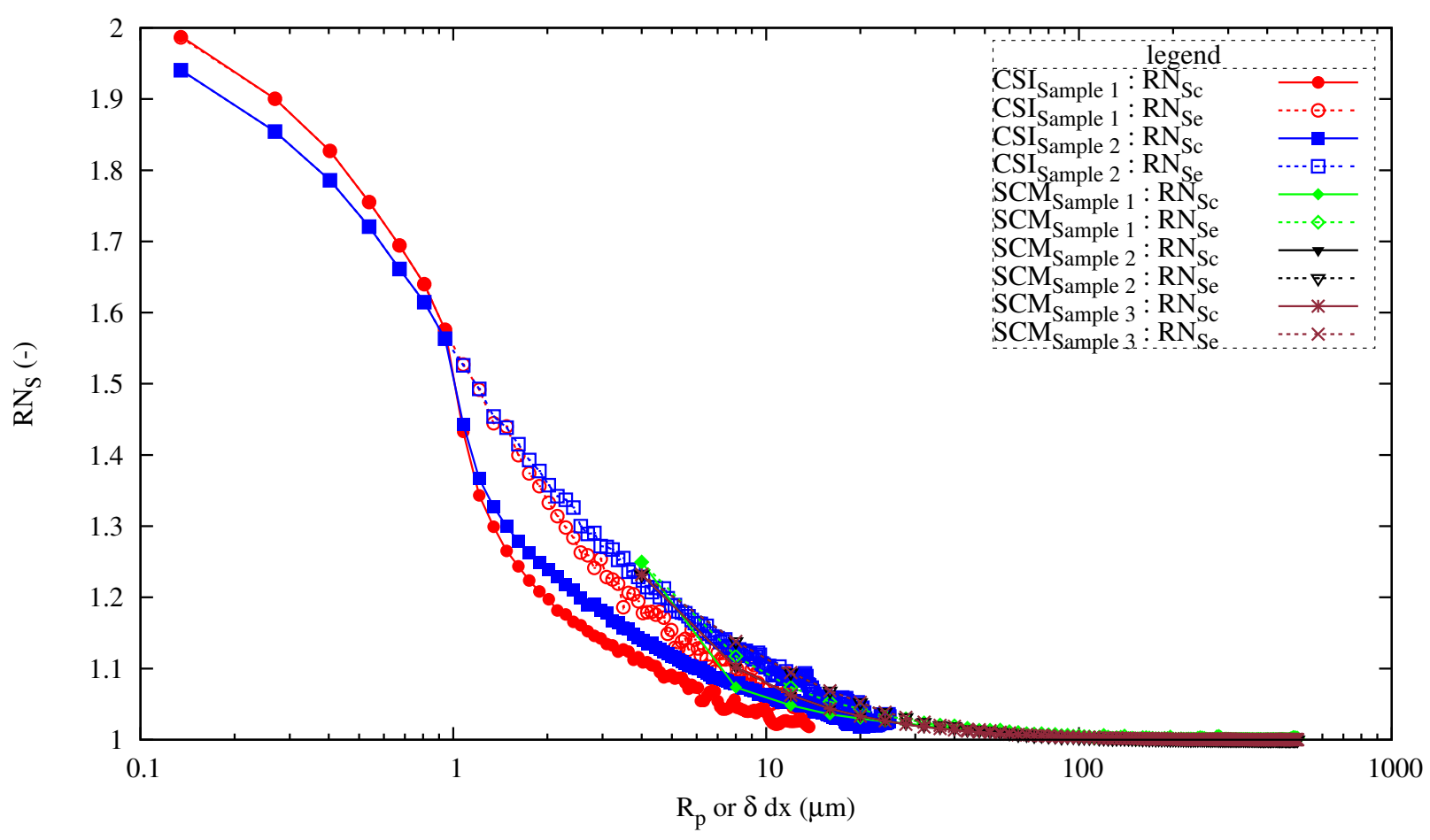

(c)

Figure 9: Roughness $R N_{S}$ numbers in the case of unpolished samples : (a) results from SCM, (b) results from CSI, (c) results SCM vs CSI 


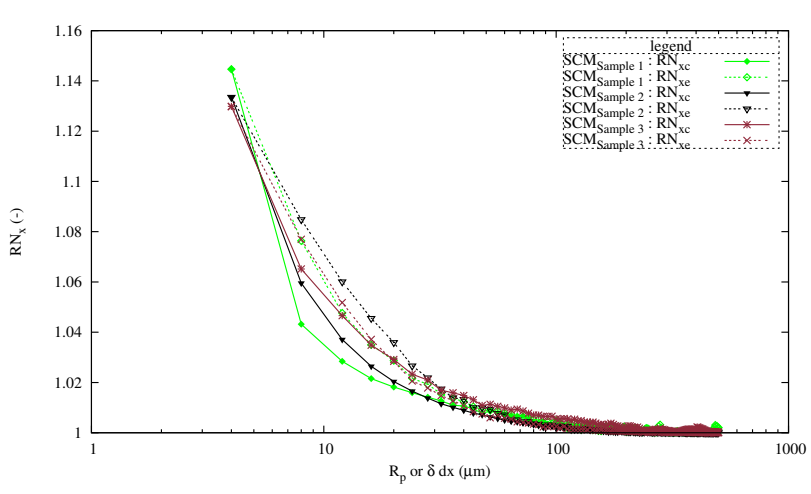

(a)

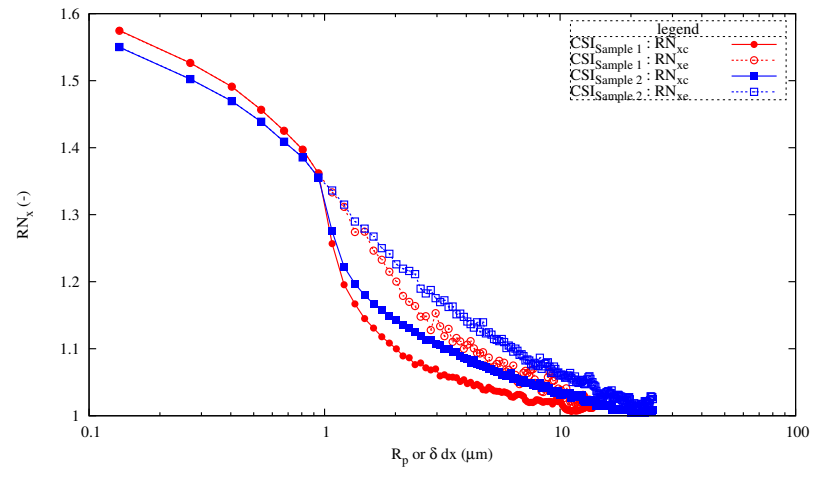

(b)

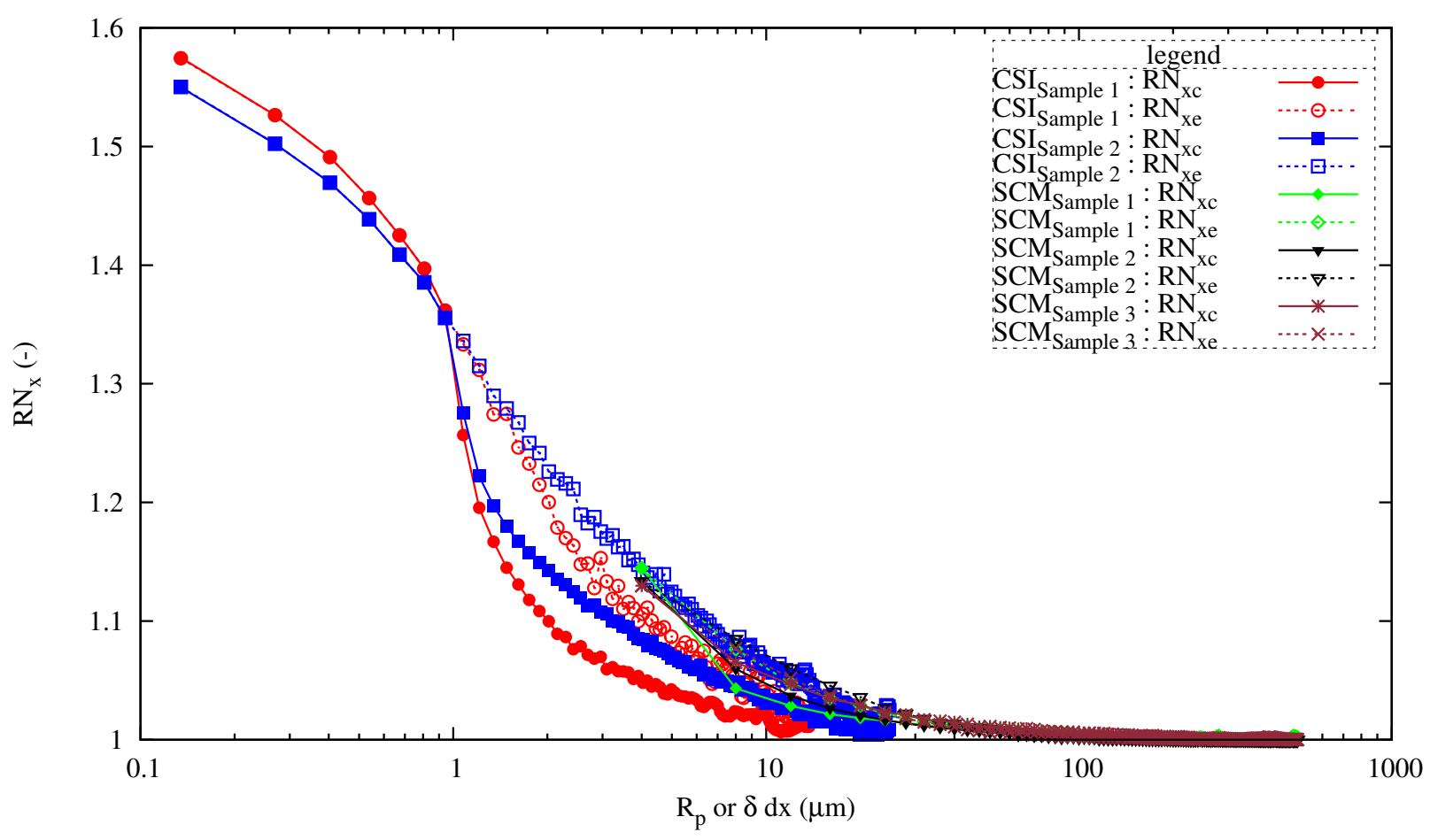

(c)

Figure 10: Roughness $R N_{x}$ numbers along $x$ axis in the case of unpolished samples : (a) results from SCM, (b) results from CSI, (c) results SCM vs CSI 


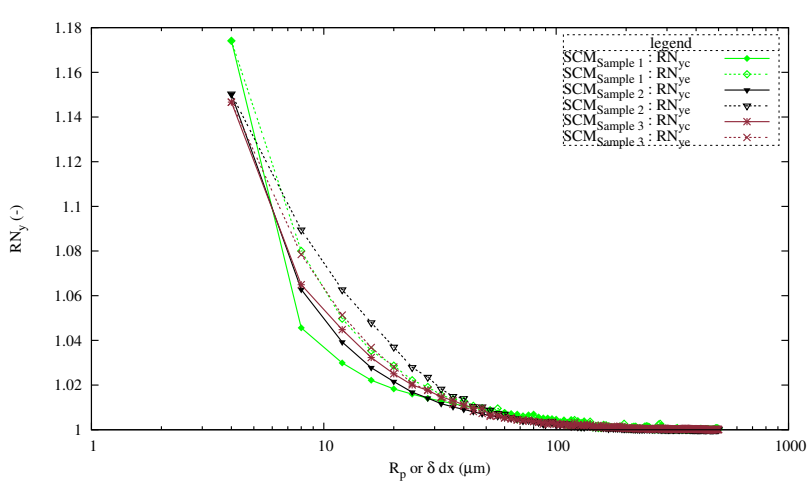

(a)

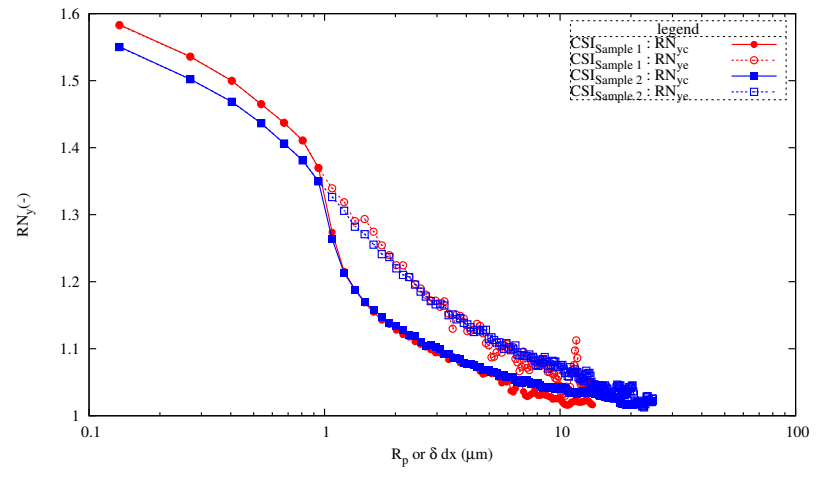

(b)

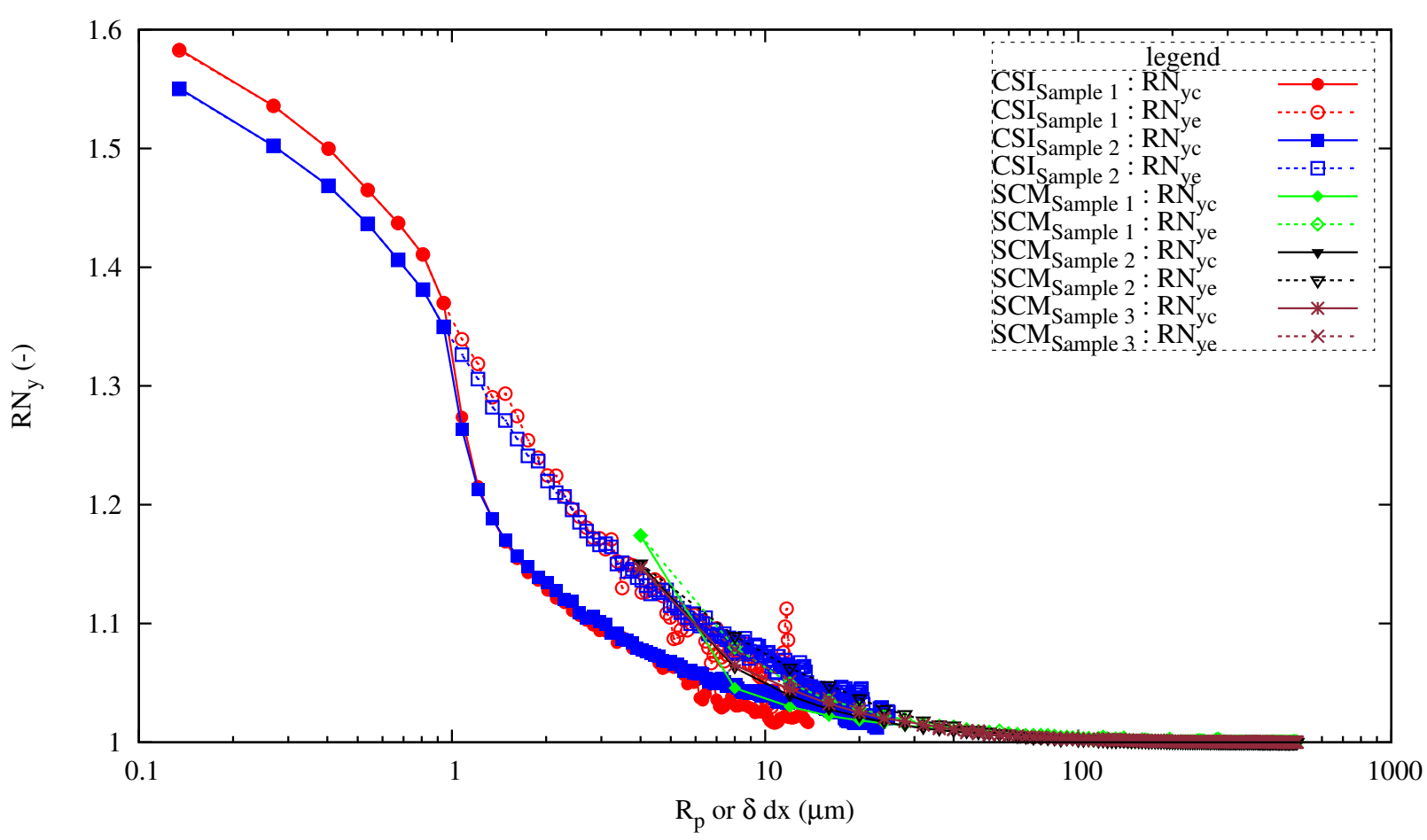

(c)

Figure 11: Roughness $R N_{y}$ numbers along $y$ axis in the case of unpolished samples : (a) results from SCM, (b) results from CSI, (c) results SCM vs CSI 


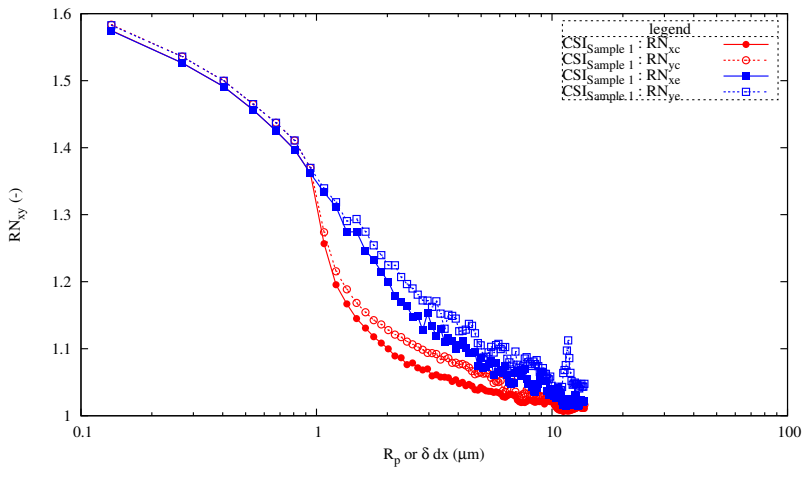

(a)

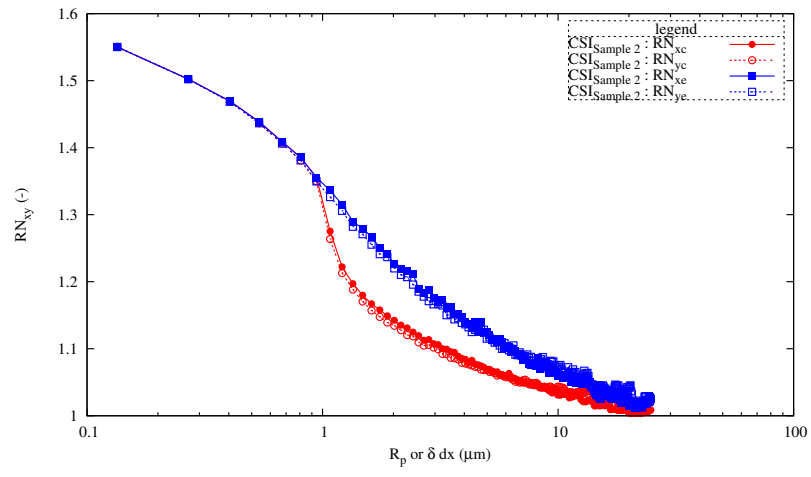

(b)

Figure 12: Roughness numbers along both axes in the case of CSI measurements : (a) results from Sample 1, (b) results from Sample 2 


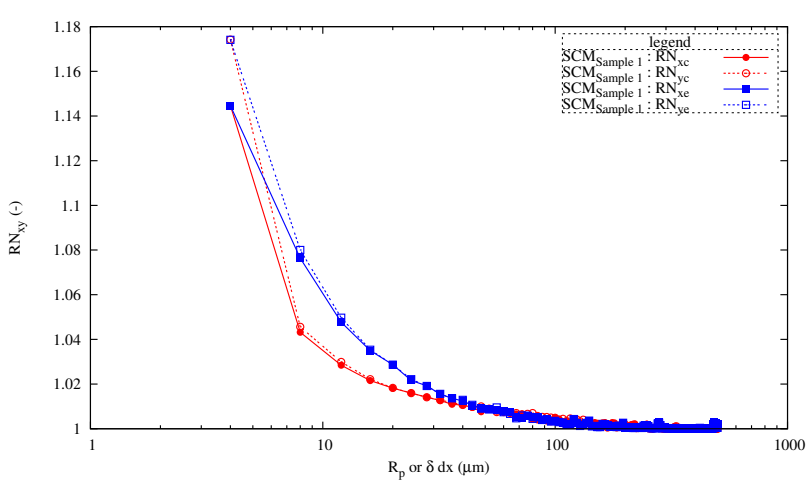

(a)

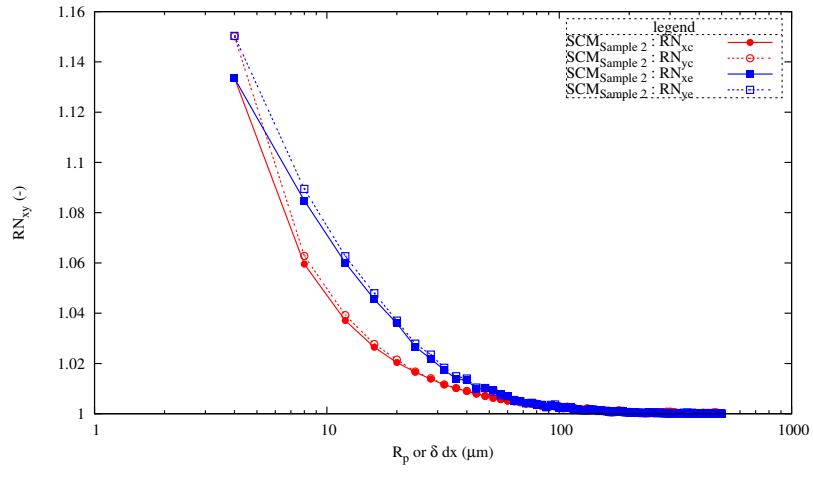

(b)

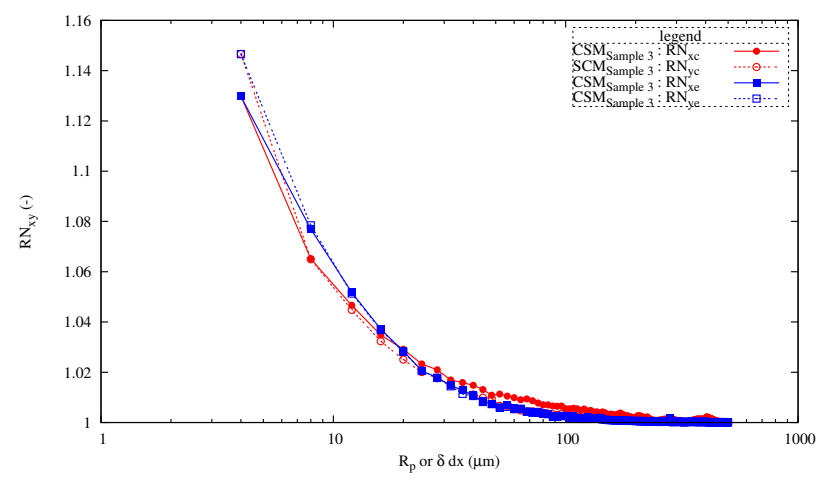

(c)

Figure 13: Roughness numbers along both axes in the case of SCM measurements : (a) results from Sample 1, (b) results from Sample 2, (c) results from Sample 3 